\title{
Development of a small molecule that corrects misfolding and increases secretion of $\mathrm{Z} \alpha_{1}$-antitrypsin
}

\author{
David A Lomas ${ }^{1,{ }^{*}}$ (D), James A Irving ${ }^{1}$ (D), Christopher Arico-Muendel ${ }^{2}$, Svetlana Belyanskaya ${ }^{2}$, \\ Andrew Brewster ${ }^{3}$, Murray Brown ${ }^{3}$, Chun-wa Chung ${ }^{3}$, Hitesh Dave ${ }^{3}$, Alexis Denis ${ }^{4}$, Nerina Dodic ${ }^{4}$, \\ Anthony Dossang ${ }^{3}$, Peter Eddershaw ${ }^{3}$, Diana Klimaszewska ${ }^{3}$, Imran $\mathrm{Haq}^{1}$, Duncan S Holmes ${ }^{3}$, \\ Jonathan P Hutchinson ${ }^{3}$, Alistair M Jagger ${ }^{1}$, Toral Jakhria ${ }^{3}$, Emilie jigorel ${ }^{4}$, John Liddle ${ }^{3}$, Ken Lind ${ }^{2}$, \\ Stefan J Marciniak ${ }^{5}$, Jeff Messer ${ }^{2}$, Margaret Neu ${ }^{3}$, Allison Olszewski ${ }^{2}$, Adriana Ordonez ${ }^{5}$, \\ Riccardo Ronzoni ${ }^{1}$ D, James Rowedder ${ }^{3}$, Martin Rüdiger ${ }^{3}$, Steve Skinner ${ }^{2}$, Kathrine J Smith ${ }^{3}$, \\ Rebecca Terry ${ }^{3}$, Lionel Trottet ${ }^{4}$, lain Uings ${ }^{3}$, Steve Wilson ${ }^{3}$, Zhengrong Zhu ${ }^{2}$ \& Andrew C Pearce ${ }^{3,{ }^{* *}}$ (D)
}

\begin{abstract}
Severe $\alpha_{1}$-antitrypsin deficiency results from the $Z$ allele (Glu342Lys) that causes the accumulation of homopolymers of mutant $\alpha_{1}$-antitrypsin within the endoplasmic reticulum of hepatocytes in association with liver disease. We have used a DNAencoded chemical library to undertake a high-throughput screen to identify small molecules that bind to, and stabilise $Z \alpha_{1}$-antitrypsin. The lead compound blocks $Z \alpha_{1}$-antitrypsin polymerisation in vitro, reduces intracellular polymerisation and increases the secretion of $Z \alpha_{1}$-antitrypsin threefold in an iPSC model of disease. Crystallographic and biophysical analyses demonstrate that GSK716 and related molecules bind to a cryptic binding pocket, negate the local effects of the $Z$ mutation and stabilise the bound state against progression along the polymerisation pathway. Oral dosing of transgenic mice at $100 \mathrm{mg} / \mathrm{kg}$ three times a day for 20 days increased the secretion of $Z \alpha_{1}$-antitrypsin into the plasma by sevenfold. There was no observable clearance of hepatic inclusions with respect to controls over the same time period. This study provides proof of principle that "mutation ameliorating" small molecules can block the aberrant polymerisation that underlies $Z \alpha_{1}$-antitrypsin deficiency.
\end{abstract}

Keywords emphysema; liver disease; protein misfolding; small molecule corrector; $\alpha_{1}$-antitrypsin deficiency

Subject Categories Genetics, Gene Therapy \& Genetic Disease; Pharmacology \& Drug Discovery
DOI 10.15252/emmm.202013167| Received 23 July 2020 | Revised 8 December 2020 | Accepted 10 December 2020

EMBO Mol Med (2021) e13167

\section{Introduction}

Alpha-1 antitrypsin deficiency affects 1 in 2,000 people of Northern European descent, leading to liver and lung diseases (Lomas et al, 2016). Ninety-five per cent of severe deficiency results from the " $Z$ " allele (Glu342Lys) that perturbs the folding of $\alpha_{1}$-antitrypsin resulting in the secretion of only $15 \%$ of the mature protein. The remaining protein is retained within the cell by persistent binding to molecular chaperones (Wu et al, 2003) and then either degraded via the ERAD-proteasome pathway (Le et al, 1992; Qu et al, 1996; Teckman et al, 2001) or folded into ordered polymers that may be cleared by autophagy (Teckman et al, 2004) or accumulate within the endoplasmic reticulum (ER) of hepatocytes (Lomas et al, 1992). The accumulation of polymers causes neonatal hepatitis, cirrhosis and hepatocellular carcinoma, and can sensitise the liver to damage from environmental insults such as alcohol, fat or viral hepatitis (Ordóñez et al, 2013; Strnad et al, 2019). The consequent deficiency of $\alpha_{1}$-antitrypsin within the circulation results in insufficient protection of the lungs from neutrophil elastase, leading to early-onset emphysema (Lomas et al, 2016).

The $\mathrm{Z}$ mutation lies at the head of strand 5 of $\beta$-sheet $\mathrm{A}$ of $\alpha_{1^{-}}$ antitrypsin. It perturbs the local environment, allowing population

\footnotetext{
1 UCL Respiratory, Rayne Institute, University College London, London, UK

2 GlaxoSmithKline, Cambridge, MA, USA

3 GlaxoSmithKline, Stevenage, UK

4 GlaxoSmithKline, Paris, France

5 Cambridge Institute for Medical Research, Cambridgem, UK

*Corresponding author. Tel: +44 203108 7929; E-mail: d.lomas@ucl.ac.uk

${ }^{\star *}$ Corresponding author. Tel: +44 1438 551923; E-mail: andrew.c.pearce@gsk.com
} 
of an unstable intermediate that we have termed $\mathrm{M}^{*}$ (Dafforn et al, 1999 ) in which $\beta$-sheet $A$ opens and the upper part of helix $F$ unwinds (Gooptu et al, 2000; Nyon et al, 2012). Polymerisation from this state involves insertion of the RCL into $\beta$-sheet A with a domain-swap of the $\mathrm{C}$-terminal region providing the inter-subunit linkage (Huang et al, 2016; Faull et al, 2020; Laffranchi et al, 2020). The resulting polymer is deposited within hepatocytes.

The aim of our work was to develop a small molecule corrector of $\mathrm{Z} \alpha_{1}$-antitrypsin folding that was able to block the formation of polymers within the ER of hepatocytes and that was suitable for oral dosing as a potential treatment for $\alpha_{1}$-antitrypsin deficiency. To achieve this, we needed to overcome a number of challenges: (i) the drug target is a highly mobile folding intermediate located in the ER; (ii) disparity in the size of the interface between a small molecule and the large protein-protein interaction that it is designed to block; (iii) oral dosing greatly restricts suitable chemical space; (iv) as a non-classical drug target, small molecule binders may well not be well-represented in compound screening libraries; and (v) the relatively high concentration of circulating monomeric $\mathrm{Z} \alpha_{1}$-antitrypsin $(\sim 5 \mu \mathrm{M})$, even in individuals with severe plasma deficiency, represents a high-affinity sink for compound, restricting its access to the target in the hepatocyte and requiring high total blood concentrations of drug to achieve sufficient free drug concentration and target engagement in the liver.

\section{Results}

\section{Identification of GSK716 through encoded library technology screening, structure-guided drug design and cellular profiling}

$\mathrm{Z} \alpha_{1}$-antitrypsin is a conformationally dynamic molecule (Lomas et al, 1992; Knaupp et al, 2010) that represents a non-classical target for drug discovery. A cell-free assay approach to hit finding was undertaken so as not to miss compounds that bind $\alpha_{1}$-antitrypsin and block polymerisation but lack the molecular properties to cross cell membranes. This comprised the following: (i) an encoded library technology (ELT) screen (Goodnow et al, 2017) of a library with a nominal diversity of $2 \times 10^{12}$ unique components to identify binders to $\mathrm{Z} \alpha_{1}$-antitrypsin and (ii) a high-throughput screen (HTS) of the GSK compound collection ( $\sim 1.7$ million compounds) for small molecules that could block polymerisation of $\mathrm{Z} \alpha_{1}$-antitrypsin. In both screening approaches, glycosylated $Z \alpha_{1}$-antitrypsin, purified from the plasma of $\mathrm{Z} \alpha_{1}$-antitrypsin homozygotes (Lomas et al, 1993), was used since this represents the disease-relevant human pathophysiological drug target that populates an intermediate on the polymerisation pathway (Knaupp et al, 2010; Irving et al, 2015). ELT selections were performed by incubating $\mathrm{Z} \alpha_{1}$-antitrypsin with DNA-encoded compound libraries for $1 \mathrm{~h}$ at 4 and $37^{\circ} \mathrm{C}$ for three rounds of selection with subsequent capture of $\mathrm{Z} \alpha_{1}$-antitrypsin using $\alpha_{1}$-antitrypsin select resin (GE Healthcare). A variation on this protocol using pre-immobilised $\mathrm{Z} \alpha_{1}$-antitrypsin was also used for library selections. In the HTS assay, polymerisation of purified $\mathrm{Z} \alpha_{1}$ antitrypsin was induced by incubation at $37^{\circ} \mathrm{C}$ for $72 \mathrm{~h}$ in the presence of test compounds, with end-point quantification of polymers performed using the polymer-specific monoclonal antibody, $2 \mathrm{C} 1$ (Miranda et al, 2010) in a TR-FRET-based immunoassay. A number of small molecules that could block polymerisation of
$\mathrm{Z} \alpha_{1}$-antitrypsin were obtained through the HTS but none progressed beyond the early lead optimisation stage. However, a single lead series of chiral hydroxy-carboxamides (GSK425) was identified from the ELT screen that also demonstrated functional activity at blocking polymerisation in the TR-FRET immunoassay (pIC50 6.5; Fig 1A and B).

Optimisation of this initial hit followed a structure-based design approach, exploiting knowledge from iterative crystal structures of small molecule ligands complexed with $\alpha_{1}$-antitrypsin. The central hydroxy carboxamide and propyl chain were found to be critical for binding to $\mathrm{Z} \alpha_{1}$-antitrypsin and hence further medicinal chemistry development focussed on modification of the phenyl and indole heterocycle. This resulted in an $\sim 100$-fold increase in potency and the discovery of the 2-oxindole GSK716 (pIC50 8.3; Fig 1A and B).

\section{GSK716 is a potent inhibitor of polymerisation in vitro and in cell models of disease}

GSK716 binds to $\mathrm{Z} \alpha_{1}$-antitrypsin with a high-affinity mean pKD $8.5 \pm 0.12(n=18)$ as determined by a competition binding assay with a fluorescently labelled derivative (Fig 1C). The binding demonstrates selectivity with a 50-fold lower affinity for plasmapurified wild-type $\mathrm{M} \alpha_{1}$-antitrypsin at mean pKD $6.8 \pm 0.18$ ( $n=10$; Fig $1 \mathrm{C})$. The shape of the curves and native mass spectrometry (not shown) are consistent with a single high-affinity compound binding site. No binding of the fluorescent derivative to polymers of $\mathrm{Z} \alpha_{1}$-antitrypsin was observed, indicating conformational selectivity for the monomeric protein (Fig 1D). The rate of interaction of the compound with the target was monitored through changes in intrinsic tryptophan fluorescence (Dafforn et al, 1999); this property was used to determine the second-order association rate constants for GSK716 binding to $\mathrm{Z}\left(4.1 \times 10^{4} \mathrm{M}^{-1} \mathrm{~s}^{-1}\right)$ and $\mathrm{M} \quad \alpha_{1}$-antitrypsin $\left(2.1 \times 10^{2} \mathrm{M}^{-1} \mathrm{~s}^{-1}\right.$; Fig $1 \mathrm{E}$ and $\left.\mathrm{F}\right)$. From the association rate constants and the affinity values, first-order dissociation rate constants were calculated and found to be of the same order of magnitude for $\mathrm{Z}\left(6.1 \times 10^{-5} \mathrm{~s}^{-1}\right)$ and $\mathrm{M} \alpha_{1}$-antitrypsin $\left(1.6 \times 10^{-5} \mathrm{~s}^{-1}\right)$. Therefore, the selectivity of the compound for $\mathrm{Z}$ over $\mathrm{M} \alpha_{1}$-antitrypsin is dominated by the difference in the rate of association rather than dissociation.

The ability of GSK716 to block $\mathrm{Z} \alpha_{1}$-antitrypsin polymerisation in the ER during folding was assessed by adding GSK716 to CHO-TETON-Z-A1AT cells (Ordóñez et al, 2013) with simultaneous induction of $\mathrm{Z} \alpha_{1}$-antitrypsin expression using doxycycline. In comparison with controls, GSK716 completely blocked the intracellular formation of $\mathrm{Z} \alpha_{1}$-antitrypsin polymers, as measured by staining with the $2 \mathrm{C} 1$ anti- $Z$ $\alpha_{1}$-antitrypsin polymer monoclonal antibody (mean pIC50 $=6.3 \pm 0.23 ; n=71 ;$ Fig $2 \mathrm{~A}$ and $\mathrm{B}$ ). It also increased the secretion of $\mathrm{Z} \alpha_{1}$-antitrypsin (mean pEC50 $6.2 \pm 0.23 ; n=74$; Fig $2 \mathrm{~B}$ ). Similar potency between the effects on secretion and polymerisation was observed throughout members of the lead series supporting the hypothesis that these effects are caused by the same pharmacological mode of action. GSK716 had a similar effect on the secretion and polymerisation of constitutively expressed $Z \alpha_{1}$-antitrypsin in iPSC-derived human hepatocytes with the $\mathrm{ZZ} \alpha_{1}$-antitrypsin genotype (Yusa et al, 2011). It inhibited polymerisation and increased secretion with a mean pIC50 of $6.4 \pm 0.45(n=16)$ and mean pEC50 of $6.5 \pm 0.37 \quad(n=14)$, respectively, inducing an approximately threefold increase in secreted levels of $\mathrm{Z} \alpha_{1}$-antitrypsin 
A<smiles>CCC[C@H](NC(=O)c1cccc2c1CC(=O)N2)[C@H](CCC)c1cccc(I)c1C</smiles><smiles>CCCCC(NC(=O)c1ccc2cc[nH]c2c1)C(O)c1ccccc1</smiles>

GSK 425

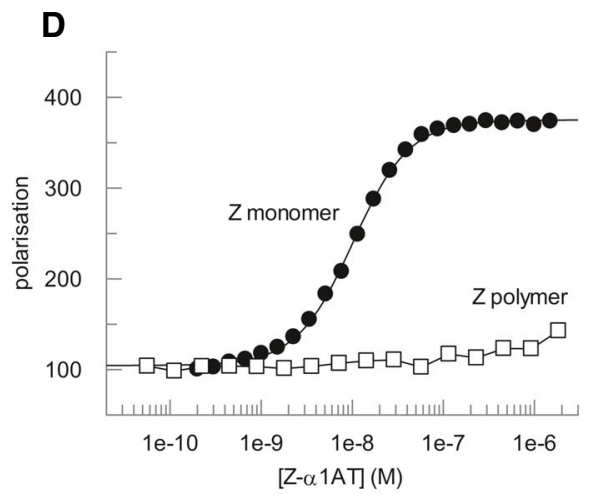

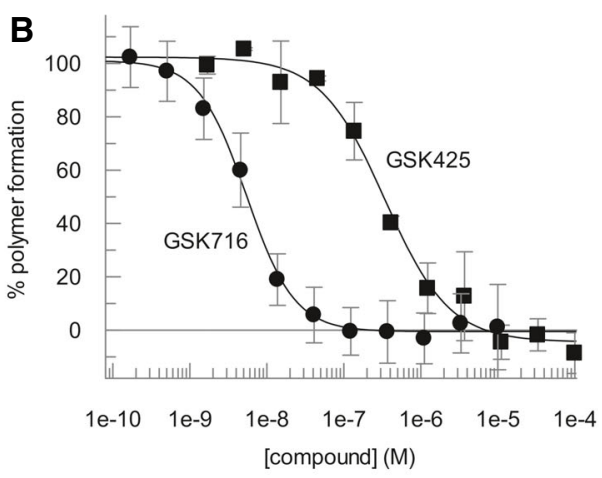

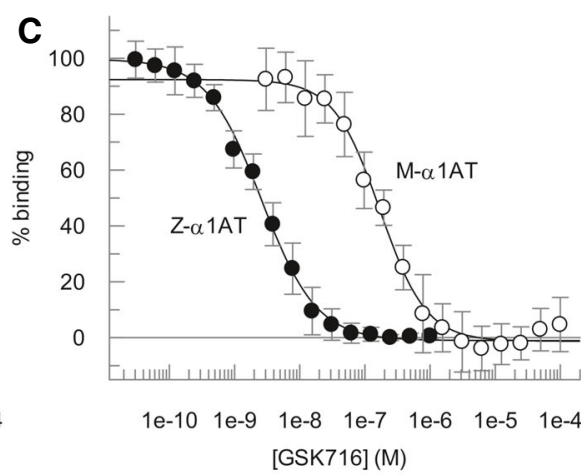

E

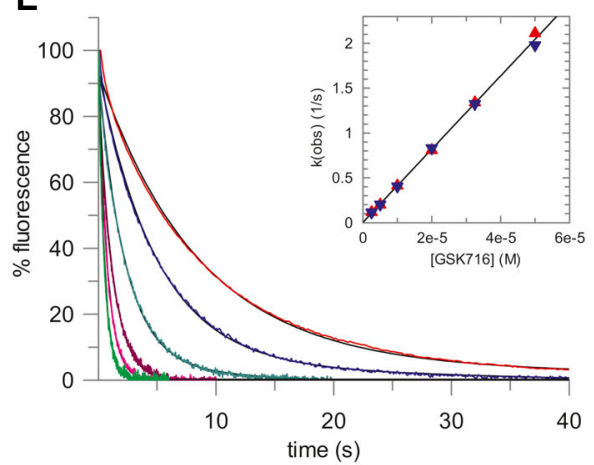

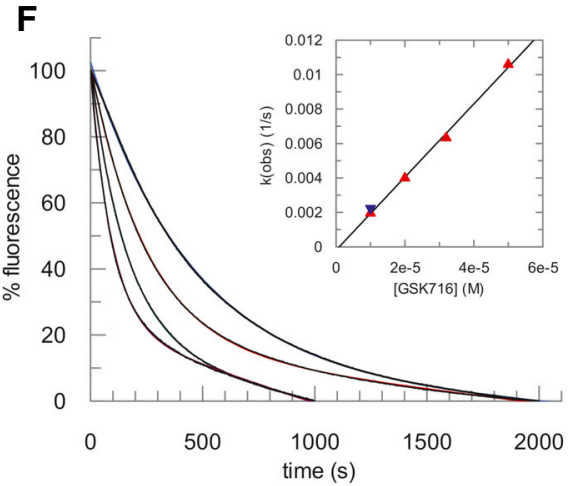

Figure 1. Characteristics of the lead series of chiral hydroxy-carboxamides identified from the ELT screen.

A The structure of GSK425, identified from the ELT screen, and the derived compound GSK716 obtained through a structure-based design pipeline.

B The degree of polymerisation of $\mathrm{Z} \alpha_{1}$-antitrypsin after $72 \mathrm{~h}$ at $37^{\circ} \mathrm{C}$, as determined by an end-point immunoassay using the $2 \mathrm{Cl}$ monoclonal antibody, in varying concentrations of compound (shown in panel A). Modification of the phenyl and indole heterocycle of GSK425 (pIC50 6.5) resulted in an $~ 100$-fold increase in potency and the discovery of the 2-oxindole GSK716 (pIC50 8.3). Data presented as mean \pm SD, $n=2$ (GSK425) and $n=25$ (CSK716).

C GSK716 binds to Z $\alpha_{1}$-antitrypsin with a high-affinity mean pKD of $8.5 \pm 0.12(n=18)$ as determined by a competition binding assay with a fluorescently labelled derivative. There was a 50-fold lower affinity for plasma-purified wild-type $M \alpha_{1}$-antitrypsin, with a mean pKD of $6.8 \pm 0.18$ ( $\left.n=10\right)$. Data presented as mean \pm SD.

D The compound bound to monomeric but not polymeric $Z \alpha_{1}$-antitrypsin (Z $\alpha_{1}$-AT) as reported by fluorescence polarisation of an Alexa-488-labelled variant of CSK716.

E Representative curves reporting the interaction of different concentrations of GSK716 with $Z \alpha_{1}$-antitrypsin based on changes in intrinsic tryptophan fluorescence. Based on the concentration dependence (inset), the second-order rate constant of association was found to be $4.1 \times 10^{4} \mathrm{M}^{-1} \mathrm{~s}^{-1}$.

$\mathrm{F}$ The association of GSK716 with $\mathrm{M} \alpha_{1}$-antitrypsin, giving a second-order rate constant of $2.1 \times 10^{2} \mathrm{M}^{-1} \mathrm{~s}^{-1}$.

(Fig 2C and D). GSK716 treatment reduced the levels of intracellular $\mathrm{Z} \alpha_{1}$-antitrypsin polymer compared with cells assessed before compound addition (Fig $2 \mathrm{C}$ ), demonstrating that polymers can be cleared over the time course of the experiment, and that accumulation of polymers is reversible in ZZ-iPSC hepatocytes.

The pre-treatment of $\mathrm{CHO}$ cells induced to express $\mathrm{Z} \alpha_{1}$-antitrypsin with GSK716 significantly reduced the formation of soluble and insoluble polymers (Fig 2E; compare PRE with time 0). To investigate the ability of GSK716 to protect cells from sensitisation to a secondary insult, $\mathrm{Z} \alpha_{1}$-antitrypsin expression was induced in CHO-TET-ON-Z-A1AT cells in the presence or absence of $10 \mu \mathrm{M}$ GSK716 before exposure to increasing concentrations of the ER stressor tunicamycin (Ordóñez et al, 2013). Cells expressing wildtype $M \alpha_{1}$-antitrypsin were less susceptible to tunicamycin toxicity than cells expressing $\mathrm{Z} \alpha_{1}$-antitrypsin in a cell viability assay (Fig 2F). GSK716 restored sensitivity of $Z \alpha_{1}$-antitrypsin expressing cells to that of the wild-type control cells. The effect of GSK716 on Z $\alpha_{1}$-antitrypsin was confirmed in pulse-chase experiments (Fig $2 \mathrm{G}$ and $\mathrm{H})$.
These data collectively show that the small molecule completely blocks the intracellular polymerisation of $\mathrm{Z} \alpha_{1}$-antitrypsin and increases secretion of the monomeric protein.

\section{GSK716 binds to a novel cryptic binding site}

A high-resolution crystal structure of $\alpha_{1}$-antitrypsin complexed with the lead compound GSK716 was generated by soaking compound into apo $\alpha_{1}$-antitrypsin crystals (Table 1 ). The structure reveals that interaction with the compound induces the formation of a cryptic binding site that is not evident in apo structures, at the top of $\beta$ sheet A behind strand 5. This region is referred to as the "breach" as it is the point at which the reactive centre loop first inserts during protease inhibition (Whisstock et al, 2000), and includes the site of the $\mathrm{Z}$ (Glu342Lys) mutation (Fig 3A). The structure reveals that the 2-oxindole ring of GSK716 stacks with the side chain of Trp194 whilst the carbonyl group forms a hydrogen bond with the mainchain Trp194 (Fig 3B). Trp194 adopts a new position due to rearrangement of residues Gly192 to Thr203 consistent with the change 


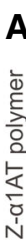

A vehicle
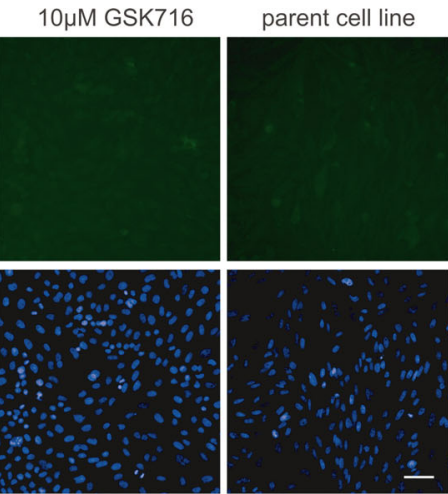

C

C day 1

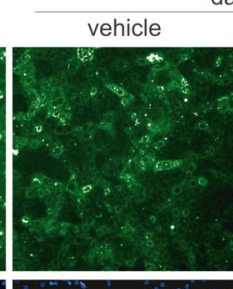

day 6
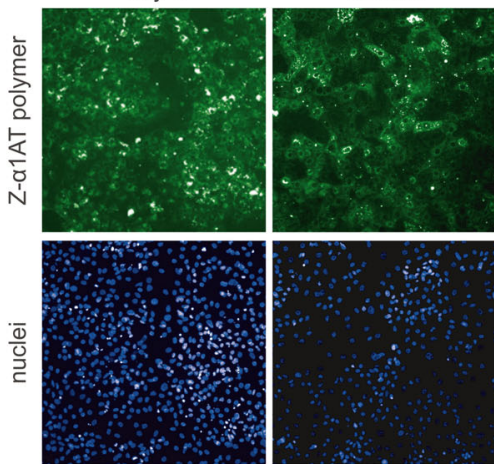

E

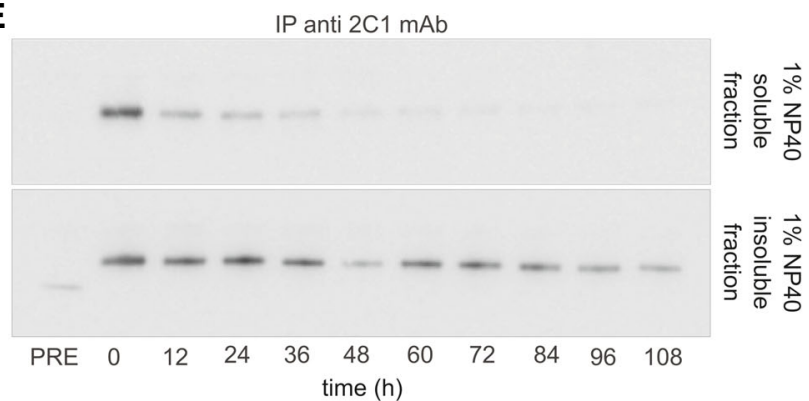

G

$0.1 \%$ DMSO

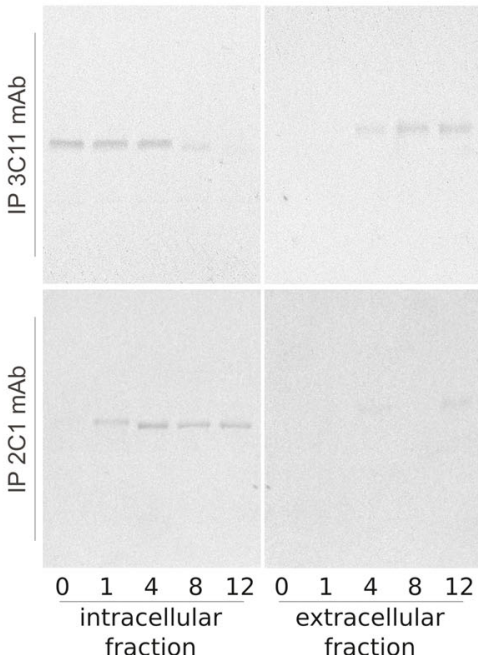

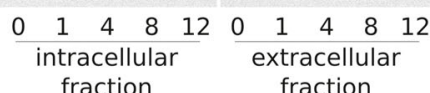
$10 \mu M$ GSK716

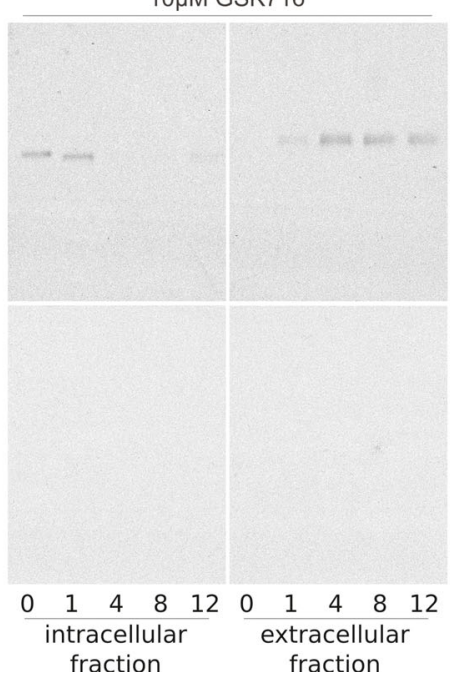

B
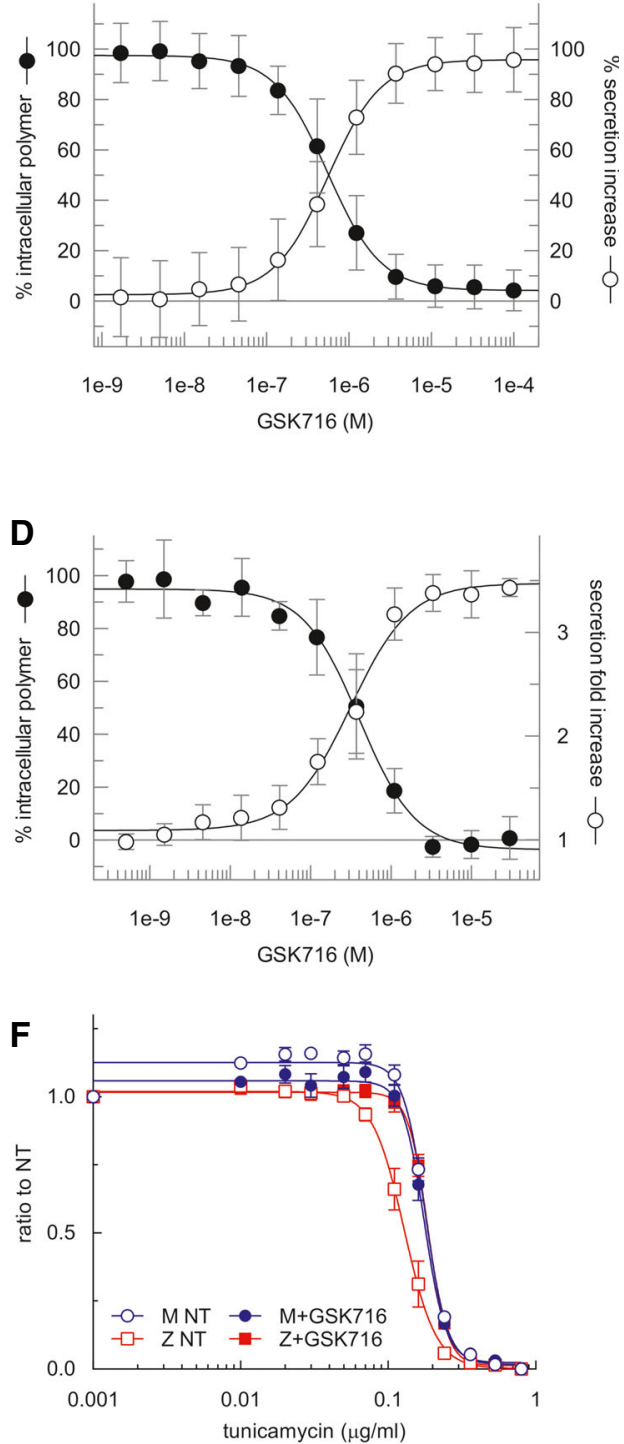

H
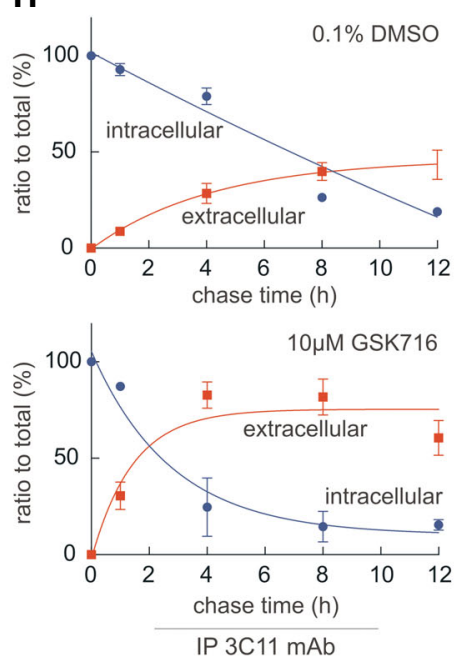

Figure 2. 
Figure 2. GSK716 inhibits polymerisation of $Z \alpha_{1}$-antitrypsin in cell models of disease.

A GSK716 was added to CHO-TET-ON-Z-A1AT cells (Ordóñez et al, 2013) with simultaneous induction of $Z \alpha_{1}$-antitrypsin expression using doxycycline, and polymer load was quantified with the $2 \mathrm{C} 1$ monoclonal antibody that is specific to pathological polymers of $\alpha_{1}$-antitrypsin (Miranda et al, 2010). The parent cell line that did not express $Z \alpha_{1}$-antitrypsin provided a negative control. CSK716 completely prevented intracellular polymer formation. Scale bar: $50 \mu \mathrm{m}$.

B Quantification of immunostained CHO-TET-ON-Z-A1AT cells showed that GSK716 reduced intracellular polymer formation and increased the secretion of Z $\alpha_{1}$ antitrypsin in a dose-dependent manner with similar potencies. Data were normalised to vehicle and a control compound from the GSK716 series at saturating concentration. Data presented as mean $\pm S D, n=61$ (secretion) and $n=67$ (polymer inhibition).

C, D GSK716 was (C) administered to iPSC-derived-hepatocytes and (D) inhibited polymerisation and increased secretion with a similar potency. It induced an approximately threefold increase in secreted levels of $Z \alpha_{1}$-antitrypsin compared with vehicle control. This was apparent even after polymers had been allowed to form. Scale bar: $100 \mu \mathrm{m}$. Data presented as mean $\pm \mathrm{SD}, n=8$ (secretion) and $n=6$ (polymer inhibition).

E CHO tetracycline-inducible cells expressing $Z \alpha_{1}$-antitrypsin were induced with $0.5 \mu \mathrm{g} / \mathrm{ml}$ doxycycline for $48 \mathrm{~h}$ and treated with $10 \mu \mathrm{M}$ GSK716. Cells were then lysed in 1\% v/v NP-40 buffer at different time points (0, 12, 24, 36, 48, 60, 72, 84, 96 and 108 h). For every time point, NP-40-soluble and NP-40-insoluble fractions were separated and immunoprecipitated with the $2 \mathrm{Cl} \mathrm{mAb}$ and resolved by $4-12 \% \mathrm{w} / \mathrm{v}$ SDS-PAGE and $\alpha_{1}$-antitrypsin detected by immunoblotting. PRE indicates cells pre-treated for $48 \mathrm{~h}$ with $10 \mu \mathrm{M}$ GSK716 and induced for the same time with $0.5 \mu \mathrm{g} / \mathrm{ml}$ doxycycline. The rate of clearance of soluble and insoluble polymer is shown.

F $\quad$ CHO-inducible cells expressing either wild-type $\mathrm{M}$ or $\mathrm{Z} \alpha_{1}$-antitrypsin were induced with $0.5 \mu \mathrm{g} / \mathrm{ml}$ doxycycline and treated with $10 \mu \mathrm{M}$ GSK716 or with $0.1 \%$ DMSO vehicle (NT, not treated). After induction for $48 \mathrm{~h}$, cells were treated with various doses of tunicamycin for $36 \mathrm{~h}$. Cell viability was measured by Cell Counting Kit-8. The results are shown as mean $\pm \mathrm{SEM}, n=4$.

C CHO-K1 Tet-On cells expressing Z $\alpha_{1}$-antitrypsin were induced with doxycycline $(0.5 \mu \mathrm{g} / \mathrm{ml}$ ) for $48 \mathrm{~h}$. Cells were incubated with $10 \mu \mathrm{M}$ GSK716 (or $0.1 \% \mathrm{v} / \mathrm{v}$ DMSO for the control) during the induction. Culture media containing either the experimental compound or DMSO were changed every $24 \mathrm{~h}$. After the induction, cells were labelled for $10 \mathrm{~min}$ with ${ }^{35} \mathrm{~S} \mathrm{Met/Cys} \mathrm{and} \mathrm{chased} \mathrm{at} \mathrm{the} \mathrm{indicated} \mathrm{times.} \mathrm{Culture} \mathrm{media} \mathrm{were} \mathrm{collected} \mathrm{and} \mathrm{cells} \mathrm{lysed} \mathrm{in} 1 \%$ v/v NP-40 buffer. Intracellular fractions and culture media from cells expressing $Z \alpha_{1}$-antitrypsin were immunoprecipitated either with a mAb against total $\alpha_{1}$-antitrypsin (3C11) or with a polymer-specific mAb (2C1). Samples were resolved by 4-12\% w/v acrylamide SDS-PAGE and detected by autoradiography.

$H \quad$ The graphs show the effect of GSK716 on intracellular and extracellular $Z \alpha_{1}$-antitrypsin (mean \pm SEM, $n=2$ ).

in intrinsic tryptophan fluorescence induced by binding (Fig 3C). The phenyl ring and the propyl chain occupy two highly hydrophobic pockets (Fig 3D-G). Hydrogen bonds are formed between the GSK716 hydroxyl group and the Leu291 backbone, the amide nitrogen hydrogen and the backbone carbonyl oxygen of Pro289, and between the amide carbonyl and the Tyr 244 hydroxyl group (Fig 3B). This causes displacement of residues Thr339 to Ser 359 of strand $5 \mathrm{~A}$ relative to the apoprotein. Few changes are seen outside of these regions.

\section{GSK716 interferes with the transition through the polymerisation-prone intermediate $M$ * by stabilising $\beta$-sheet $A$}

Polymerisation of $\alpha_{1}$-antitrypsin involves transition through a transient intermediate state known as $\mathrm{M}^{*}$, that is readily populated by the $\mathrm{Z}$ variant (Dafforn et al, 1999; Knaupp et al, 2010). The $\mathrm{M}^{*}$ conformational ensemble appears to be a distinct species between the native state conformation and that of the final polymer. One of the hallmarks of $\mathrm{M}^{*}$ is its recognition by environment-sensitive fluorescent reporter dyes. Thermal shift assays that make use of the dye SYPRO Orange report the stability of the protein native state against heat-induced unfolding. Experiments, performed using different temperature gradients in the presence and absence of $50 \mu \mathrm{M}$ GSK716, demonstrated a marked increase in the transition midpoint temperature (Fig 4A), consistent with the stabilisation of either or both of the ground- and $\mathrm{M}^{*}$-states of $\alpha_{1}$-antitrypsin (Irving et al, 2014). Correspondingly, in a constant-temperature experiment, oligomers were generated at higher temperatures in the presence of the compound than in its absence when visualised by non-denaturing PAGE (Fig 4B). Native state stability can also be probed by equilibrium unfolding using chemical denaturants, where a peak in bisANS fluorescence corresponds with a maximally populated unfolding intermediate (James \& Bottomley, 1998). The profiles in Fig 4C show that for guanidinium hydrochloride-induced unfolding, this point occurs at a considerably higher denaturant concentration $(\sim 1.9 \mathrm{M})$ in the presence of $50 \mu \mathrm{M}$ GSK716, than in its absence $(\sim 1.3 \mathrm{M})$, reflecting an increase in the stability of the native-like state with respect to an unfolding intermediate. The association of GSK716 induced a marked quenching and blue-shift of the $\alpha_{1}$-antitrypsin intrinsic tryptophan fluorescence spectrum (Fig $4 \mathrm{D}$, inset). The rate of change in fluorescence during association of $10 \mu \mathrm{M}$ GSK716 was proportional to the propensity of $\alpha_{1}$-antitrypsin mutants to form polymers in vivo: inert (M), mild (S), moderate (Baghdad) and severe (Z) $\alpha_{1}$-antitrypsin (Fig 4D, top and bottom).

To investigate whether this activity was consistent with action as a chemical chaperone, $\mathrm{M} \alpha_{1}$-antitrypsin and $\mathrm{Z} \alpha_{1}$-antitrypsin were unfolded in vitro into $6 \mathrm{M}$ guanidine hydrochloride and rapidly refolded by snap dilution into denaturant-free buffer in the presence or absence of GSK716. Electrophoresis of the products by non-denaturing PAGE showed an anodally shifted migration for the $\mathrm{Z}$ variant in the absence of compound (Fig 4E) consistent with a misfolded by-product of $\mathrm{M}^{*}$ (Ekeowa et al, 2010), which was corrected at stoichiometric concentrations and above.

Mutations that interfere with the opening of $\beta$-sheet $A$ or that perturb its interaction with the $\mathrm{N}$-terminal portion of the reactive centre loop alter the ability of serpins to inhibit target proteases (Hood et al, 1994; Irving et al, 2014). The stoichiometry of inhibition (SI) was determined for $\mathrm{M} \quad \boldsymbol{\alpha}_{1}$-antitrypsin and $\mathrm{Z}$ $\alpha_{1}$-antitrypsin in discontinuous experiments against a model target protease, chymotrypsin. The pre-incubation of both variants with GSK716 led to a $>98 \%$ loss of protease inhibitory activity (Fig 5A). Resolution of the products of the interaction by SDS-PAGE showed full cleavage of the reactive centre loop (Fig 5B); therefore, this is not a consequence of the protease recognition site in the reactive centre loop becoming inaccessible to the enzyme. These data are consistent with a mechanism in which the compound stabilises $\beta$-sheet A against conformational change that mediates both inhibitory activity and pathological misfolding. 
Table 1. Data collection and refinement statistics.

\begin{tabular}{|c|c|}
\hline & 7AEL \\
\hline Temperature & $100 \mathrm{~K}$ \\
\hline Wavelength & 0.9763 \\
\hline Resolution range & 55.05-1.76 (1.823-1.76) \\
\hline Space group & C 121 \\
\hline Unit cell & 113.9539 .5990 .5290104 .9690 \\
\hline Total reflections & $127,818(12,581)$ \\
\hline Unique reflections & $38,772(3,853)$ \\
\hline Multiplicity & $3.3(3.3)$ \\
\hline Completeness (\%) & $99.2(99.2)$ \\
\hline Mean I/sigma (I) & $19.61(2.19)$ \\
\hline Wilson $B$-factor & 32.95 \\
\hline $\mathrm{R}$-merge & $0.02941(0.5007)$ \\
\hline $\mathrm{R}$-meas & $0.03523(0.5991)$ \\
\hline $\mathrm{CC} 1 / 2$ & $0.999(0.805)$ \\
\hline CC* & $1(0.944)$ \\
\hline Reflections used in refinement & $38,771(3,853)$ \\
\hline Reflections used for R-free & $1,908(178)$ \\
\hline R-work & $0.1969(0.3065)$ \\
\hline $\mathrm{R}$-free & $0.2259(0.3204)$ \\
\hline CC(work) & $0.958(0.739)$ \\
\hline CC(free) & $0.943(0.699)$ \\
\hline Number of non-hydrogen atoms & 3,189 \\
\hline Macromolecules & 2,868 \\
\hline Ligands & 32 \\
\hline Protein residues & 357 \\
\hline RMS (bonds) & 0.005 \\
\hline RMS (angles) & 1.02 \\
\hline Ramachandran favoured (\%) & 99 \\
\hline Ramachandran allowed (\%) & 1.1 \\
\hline Ramachandran outliers (\%) & 0 \\
\hline Rotamer outliers (\%) & 0.62 \\
\hline Clashscore & 0.52 \\
\hline Average $B$-factor & 47.79 \\
\hline Macromolecules & 46.77 \\
\hline Ligands & 36.49 \\
\hline Solvent & 59.23 \\
\hline
\end{tabular}

Statistics for the highest resolution shell are shown in parentheses.

\section{Characterisation of drug-like properties of GSK716}

GSK716 selectivity and PK properties were profiled in order to investigate the suitability of GSK716 for progression into in vivo studies and the potential for taking it forward as a clinical candidate for testing in humans. Since GSK716 results in loss of inhibitory activity of $\alpha_{1}$-antitrypsin, the effect of the compound was assessed on other closely related serpins. GSK716 did not affect the inhibitory activity of antithrombin, neuroserpin and $\alpha_{1}$-antichymotrypsin towards their cognate proteases (Fig 5C). Furthermore, there were no off-target effects in a panel of assays considered predictive of known safety liabilities that precluded further development of GSK716 (Table EV1).

Since GSK716 exhibited a good level of selectivity over the offtarget panel and over other serpins, we determined the in vitro and in vivo PK properties of the molecule with a view to exploring target engagement in vivo. GSK716 has a measured ChromLogD (pH7.4) of 3.8, low binding to human serum albumin (84.2\%) and good solubility of amorphous drug substance in FaSSIF $(969 \mu \mathrm{g} /$ $\mathrm{ml}$ ). Permeability in MDR1-MDCK cells in the presence of pgp inhibitor GF120918 was high at 248 and $240 \mathrm{~nm} / \mathrm{s}$ for the apical to basal and basal to apical directions, respectively (N53531-23 for DI). GSK716 exhibited low metabolic clearance in human hepatocytes $(0.31 \mathrm{ml} / \mathrm{min} / \mathrm{g}$ tissue), with moderate to high clearance in mouse hepatocytes $(4.56 \mathrm{ml} / \mathrm{min} / \mathrm{g}$ tissue $)$. It exhibited weak timedependent inhibition of CYP3A4 resulting in a 1.59-fold shift in IC50. Taken together, oral bioavailability is predicted to be high in humans, with measured $\mathrm{F}$ in rat (48\%) and dog (71\%) at $\leq 3 \mathrm{mg}$ / $\mathrm{kg}$ being consistent with $100 \%$ absorption and losses via first-pass metabolism only. Mean exposure of GSK716 in blood in the male CD-1 mouse increased with dose following single PO administration at 10,30 or $100 \mathrm{mg} / \mathrm{kg}$ (mean dose-normalised $C_{\max } 58 \pm$ $112,113 \pm 27$ and $113 \pm 27$ DNAUC $_{\text {inf }} 202 \pm 101,294 \pm 47$ and $403 \pm 246$, respectively).

\section{GSK716 increases secretion of $Z \alpha_{1}$-antitrypsin in a transgenic mouse model of $Z \alpha_{1}$-antitrypsin deficiency}

GSK716 was evaluated in a transgenic mouse model with an engineered random insertion of the human $\mathrm{Z} \alpha_{1}$-antitrypsin gene (Teckman et al, 2004). Younger hemizygous, rather than older mice, were selected as our longevity studies showed that circulating levels of $\mathrm{Z}$ $\alpha_{1}$-antitrypsin increase with age (to levels much higher than seen in patients) and these artificially high levels may act as a high-affinity sink sequestering drug and preventing bioavailability at the site of action in the liver. Further, older mice have larger $\alpha_{1}$-antitrypsin inclusions that may be more difficult to reverse and any changes would be more difficult to detect than in younger animals. The PKPD relationship of GSK716 was explored by dosing Z $\alpha_{1}$-antitrypsin transgenic animals with 10,30 or $100 \mathrm{mg} / \mathrm{kg}$ GSK716 three times a day. Blood and liver were harvested on day 6 at $3 \mathrm{~h}\left(\sim C_{\max }\right)$ and $8 \mathrm{~h}\left(C_{\mathrm{min}}\right)$ after the dose for the measurement of total and free drug in both tissues. Blood was also harvested for the measurement of monomeric $\mathrm{Z} \alpha_{1}$-antitrypsin in plasma. Total concentrations of GSK716 were determined by LC-MS/MS, and the free drug in both tissues was determined using equilibrium dialysis to determine free fraction in the samples, subsequently used to derive unbound concentrations. Blood concentrations demonstrated that the $C_{\min }$ levels of free drug were at or above $300 \mathrm{nM}$, the cellular secretion assay EC50, for the majority of the dosing period following $100 \mathrm{mg} /$ $\mathrm{kg}$ dosing, whereas 30 and $10 \mathrm{mg} / \mathrm{kg}$ doses resulted in free drug levels in blood significantly below the cellular EC50 concentrations for a large part of the dosing period. Both free and total drug concentrations of GSK716 at the targeted site of action in the liver were equivalent to those in blood (Table 2).

A significant fraction of the total $\mathrm{Z} \alpha_{1}$-antitrypsin in the circulation is in the polymeric conformation (Tan et al, 2014). There are 

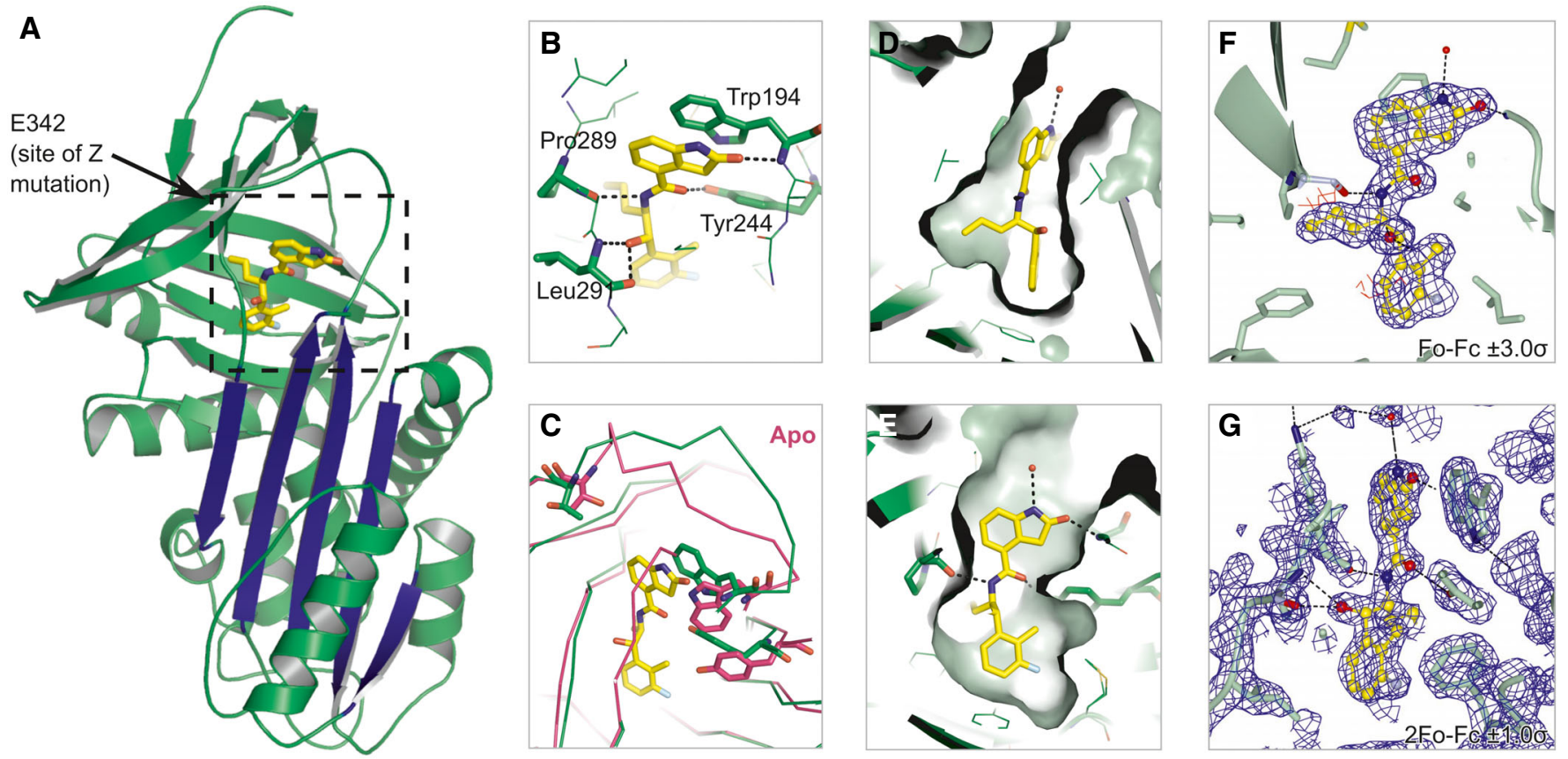

Figure 3. GSK716 binds to a novel cryptic binding site.

A Cartoon representation of $\alpha_{1}$-antitrypsin with GSK716 shown in yellow stick format. The five-stranded $\beta$-A sheet is in blue.

B Interactions of CSK716 within the cryptic site with key residues shown in stick format and hydrogen bonds in black dashed lines.

C Overlay of ribbon representation of protein chains of GSK716 complex (green) with apoprotein (purple; PDB id 2QUG (Pearce et al, 2008)) showing the altered position of Trp194 (stick format) that induces a change in conformation of the Gly192-to-Thr203 loop and re-orientation of Tyr244 (stick format).

D Surface representation of $\alpha_{1}$-antitrypsin to show propyl and phenyl pocket.

E Surface representation of $\alpha_{1}$-antitrypsin to show protein-ligand complement of the substituted phenyl and 2-oxindole rings.

F Fo-Fc omit density difference map for the ligand contoured at 3 sigma (red denotes negative, and blue denotes positive difference).

$\mathrm{G}$ Representative $2 \mathrm{Fo}-\mathrm{Fc}$ electron density map contoured at 1.0 sigma around the ligand.

no antibodies that are specific for monomeric $\mathrm{Z} \alpha_{1}$-antitrypsin and so to directly determine its concentration, a deconvolution method was developed based on immunoassays with antibodies for either total or polymeric $\alpha_{1}$-antitrypsin, and calibration curves with purified monomeric and polymeric $\mathrm{Z} \alpha_{1}$-antitrypsin. Monomeric $\mathrm{Z} \alpha_{1}$ antitrypsin was measured in plasma samples following 6 days of dosing, and levels were normalised to each animals' pre-dose control levels to account for the natural variation of $\mathrm{Z} \alpha_{1}$-antitrypsin between animals. Administration of $100 \mathrm{mg} / \mathrm{kg}$ GSK716 resulted in a mean sevenfold increase in circulating monomeric $\mathrm{Z} \alpha_{1}$-antitrypsin levels demonstrating robust target engagement in the liver (Fig 6A). Interestingly, 30 and $10 \mathrm{mg} / \mathrm{kg}$ groups also gave significant, dosedependent increases in circulating $\mathrm{Z} \alpha_{1}$-antitrypsin despite free concentrations being below the cellular EC50 for secretion for much or all of the dosing period. Total drug levels and changes in $\mathrm{Z} \alpha_{1^{-}}$antitrypsin following 3 days of dosing were indistinguishable from those following 6 days of dosing. There was no effect on circulating serum albumin after 5 days of dosing which provides evidence that GSK716 is specific for $\mathrm{Z} \alpha_{1}$-antitrypsin. Moreover, the effects are not mediated by metabolites of GSK716 as the major metabolites have much reduced or no binding to $\alpha_{1}$-antitrypsin.

Since GSK716 blocks polymer formation in cells, we explored the effect of dosing GSK716 on liver polymer levels. $Z \alpha_{1}$-antitrypsin polymers formed in CHO-TET-ON-Z-A1AT and ZZ-iPSC hepatocytes are cleared from cells with a half-life of between 8 and $48 \mathrm{~h}$ depending on whether they partition to the soluble or insoluble fractions (Ronzoni et al, 2020). Since the compound does not bind $\mathrm{Z} \alpha_{1}$-antitrypsin polymer, an effect on total liver polymer levels will be dependent on the rate at which the liver can clear the polymer already present and the rate at which polymer continues to accumulate in animals not treated with drug. GSK716 was dosed at $100 \mathrm{mg} / \mathrm{kg}$ three times a day for 20 days. Monomeric $\mathrm{Z} \alpha_{1}$-antitrypsin increased by a mean of sevenfold to eightfold in plasma samples over the predosing baseline levels on days 15 and 21 of dosing, similar to the effect in animals dosed for 3 or 6 days and consistent with sustained target engagement through the dosing period (Fig 6A). Liver polymer levels were investigated by staining with $2 \mathrm{Cl}$ anti-polymer monoclonal antibody and were scored blind by a pathologist or by quantification using an algorithm to measure all areas of positive staining (Fig EV1). There was no difference observed in total liver polymer load when assessed by manual or quantitative scoring (Fig 6B and C). There was no significant fibrosis in any of the liver sections. Intrahepatic $\alpha_{1}$-antitrypsin was also assessed by ELISA. The vast majority (95-100\%) of $\alpha_{1}$-antitrypsin within the liver was polymer with the monomer typically being below the level of detection. Treatment with GSK716 increased the monomer measured in liver homogenate by approx. fourfold in keeping with the changes seen in blood. 
A

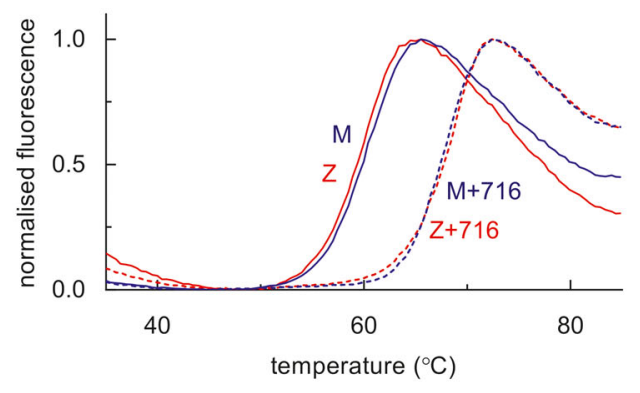

B

$-716$

$+716$

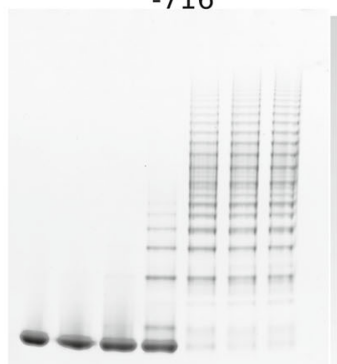

$M \stackrel{\infty}{\square} \stackrel{\sim}{6}$

$-716$

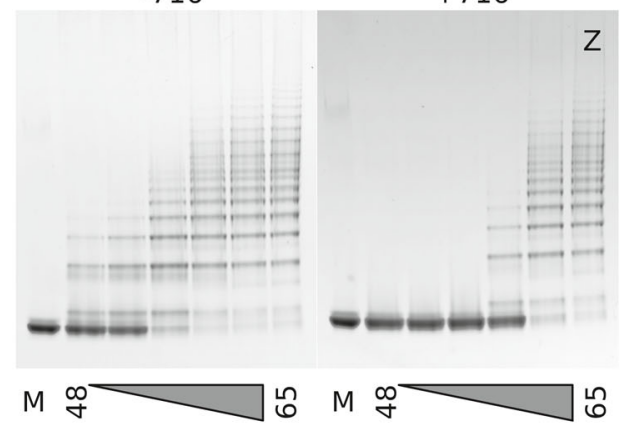

E

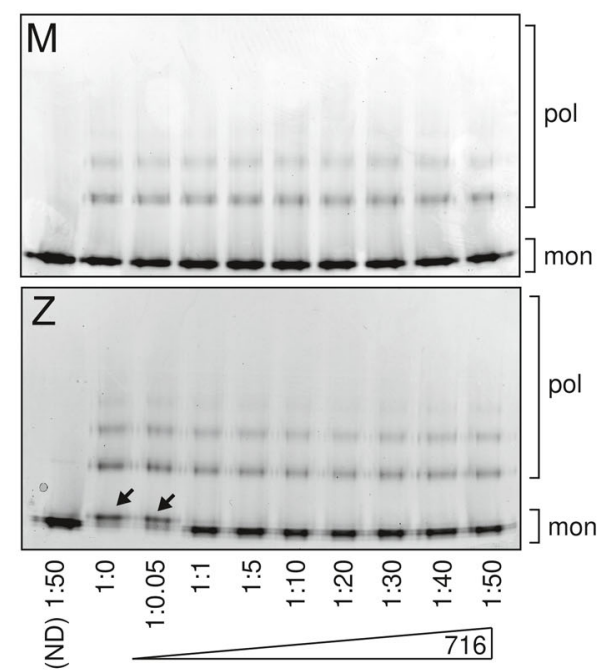

\section{C}

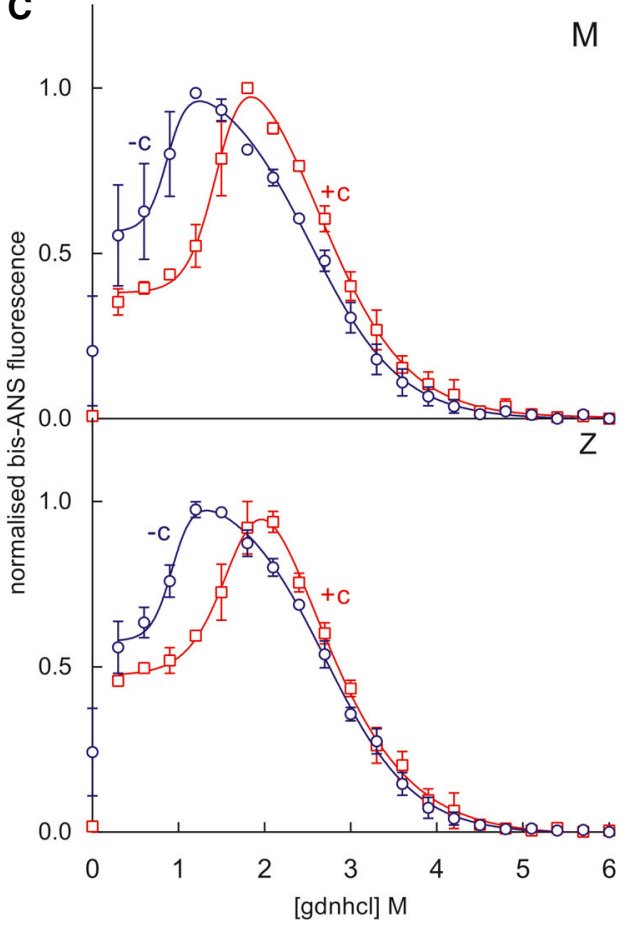

D
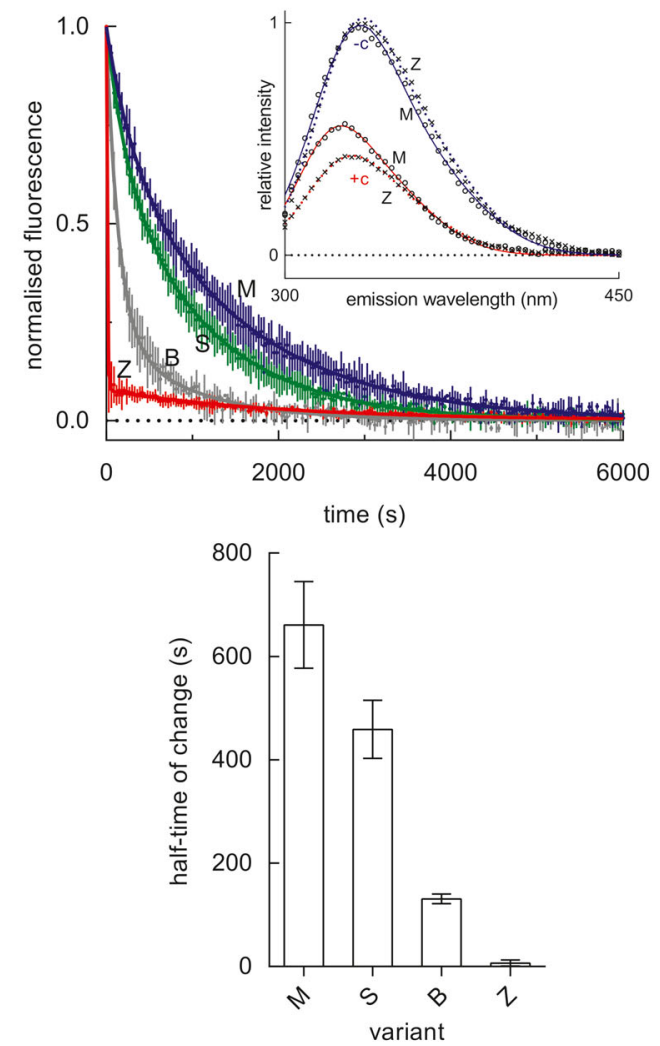

Figure 4. 


\section{Figure 4. Stabilisation of $\alpha_{1}$-antitrypsin by GSK716.}

A A SYPRO orange-based thermal stability assay, which reports the transition of $M \alpha_{1}$-antitrypsin and $Z \alpha_{1}$-antitrypsin from the native to an intermediate state over a $1^{\circ} \mathrm{C} / \mathrm{min}$ thermal ramp, in the presence and absence of $50 \mu \mathrm{M}$ GSK716.

B $M$ (above) and Z (below) $\alpha_{1}$-antitrypsin, at a concentration of $0.2 \mathrm{mg} / \mathrm{ml}$ in PBS $+5 \% \mathrm{v} / \mathrm{v}$ glycerol, were heated at a range of temperatures between 48 and $65^{\circ} \mathrm{C}$ for $4 \mathrm{~h}$ in the presence and absence of GSK716, as indicated. The oligomerisation state was determined by non-denaturing PAGE electrophoresis; the lane denoted "M" contains the unheated monomeric control.

C $M \alpha_{1}$-antitrypsin and $Z \alpha_{1}$-antitrypsin were subjected to equilibrium unfolding into different concentrations of guanidine hydrochloride (gdnhcl) in the presence and absence of GSK716, with bis-ANS dye added to report the presence of the unfolded intermediate. The normalised fluorescence intensity data were fitted with an equation describing a three-state unfolding curve. Values shown are the mean of three independent experiments, and the error bars represent \pm SEM.

D Top panel, the association of GSK716 induced a marked quenching and blue-shift of the $\alpha_{1}$-antitrypsin intrinsic tryptophan fluorescence spectrum with respect to unbound protein (inset graph). The association of $10 \mu \mathrm{M}$ GSK716 with four $\alpha_{1}$-antitrypsin variants that vary in their propensity to polymerise, ranging from inert (M), to mild $(S)$, moderate (Baghdad denoted " $B$ ") and severe (Z). Representative progress curves of the change in intrinsic tryptophan fluorescence at $330 \mathrm{~nm}$ for $0.2 \mathrm{mg}$ / $\mathrm{ml}$ protein are shown. Bottom panel, the half-time of association calculated from three such independent experiments (error bars are \pm SEM) show a correspondence with the polymerisation propensity of the four variants. The change in $Z \alpha_{1}$-antitrypsin fluorescence was faster than the dead-time of the apparatus ( $\left.10 \mathrm{~s}\right)$, and scaling was with reference to unbound intensity.

E Non-denaturing PAGE characterisation of the conformational state of $M \alpha_{1}$-antitrypsin and $Z \alpha_{1}$-antitrypsin, after rapidly refolding by snap dilution from $6 \mathrm{M}$ urea in the presence or absence of GSK716 at the molar ratios indicated. The migration of polymers (pol) and monomers (mon) is shown. Arrows indicate the misfolded byproduct $\mathrm{M}^{*}$ arising at sub-stoichiometric concentrations of compound.
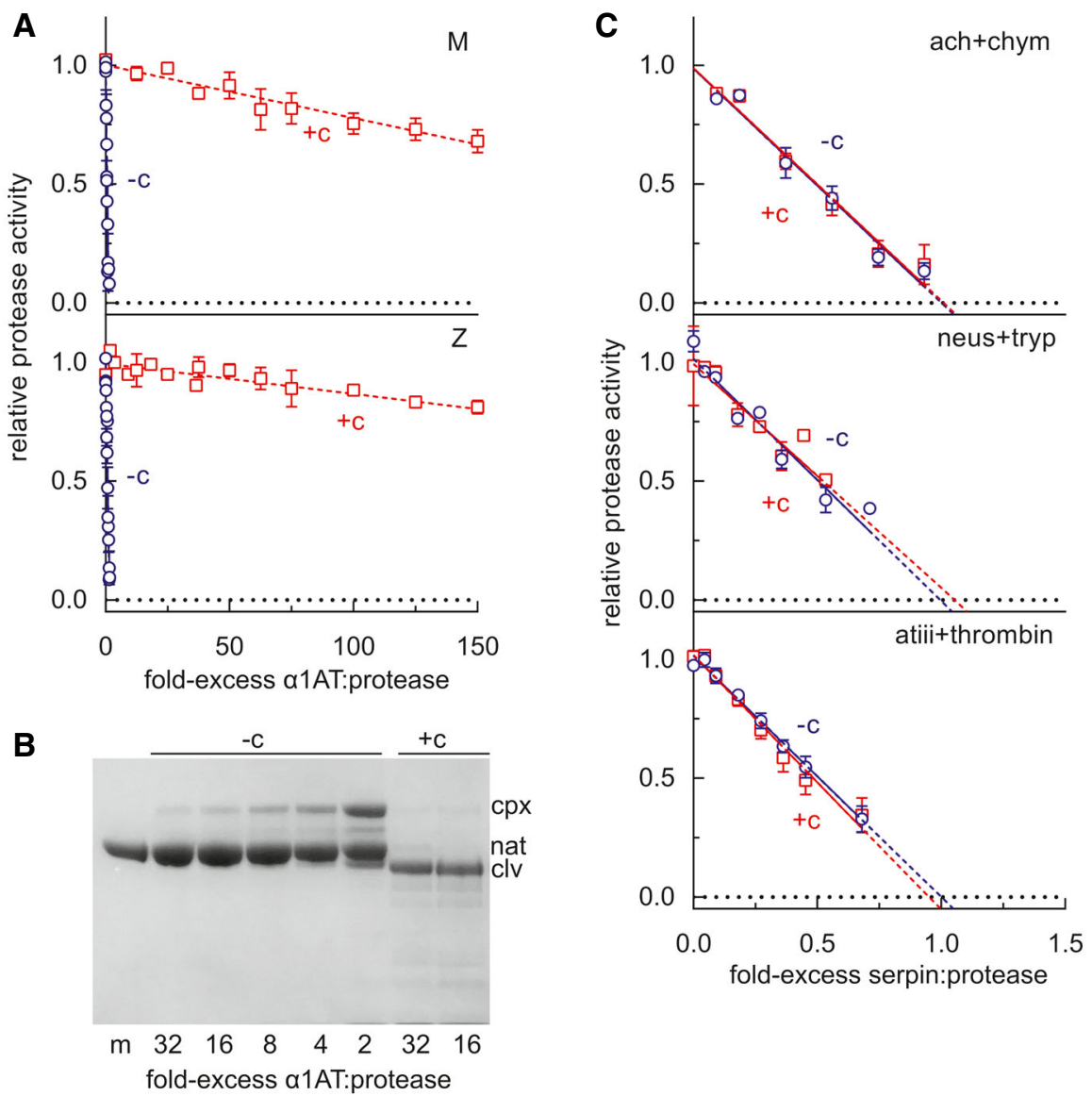

\section{Figure 5. The effect of GSK716 on serpin inhibitory activity.}

A $\alpha_{1}$-Antitrypsin was incubated at varying molar ratios with the model protease bovine $\alpha$-chymotrypsin, and the residual protease activity determined. The intercept of the regression with the abscissa reflects the number of molecules of $\alpha_{1}$-antitrypsin required to inhibit one molecule of chymotrypsin in the presence $(+c)$ and absence $(-c)$ of $50 \mu \mathrm{M}$ GSK716. Error bars reflect \pm SEM of three independent experiments.

B $\mathrm{M} \alpha_{1}$-antitrypsin was incubated with different molar ratios of chymotrypsin and resolved by SDS-PAGE. The position of covalent $\alpha_{1}$-antitrypsin-chymotrypsin complex (cpx), native (nat) and cleaved (clv) is shown.

C The inhibitory activity of $\alpha_{1}$-antichymotrypsin against chymotrypsin (ach + chym), neuroserpin against trypsin (neus + tryp), and antithrombin against thrombin (atiii + thrombin) was determined in the presence and absence of GSK716. Error bars reflect \pm SD of two independent experiments. 
Table 2. Unbound and total drug concentrations of GSK716 following dosing in $Z \alpha_{1}$-antitrypsin transgenic mice.

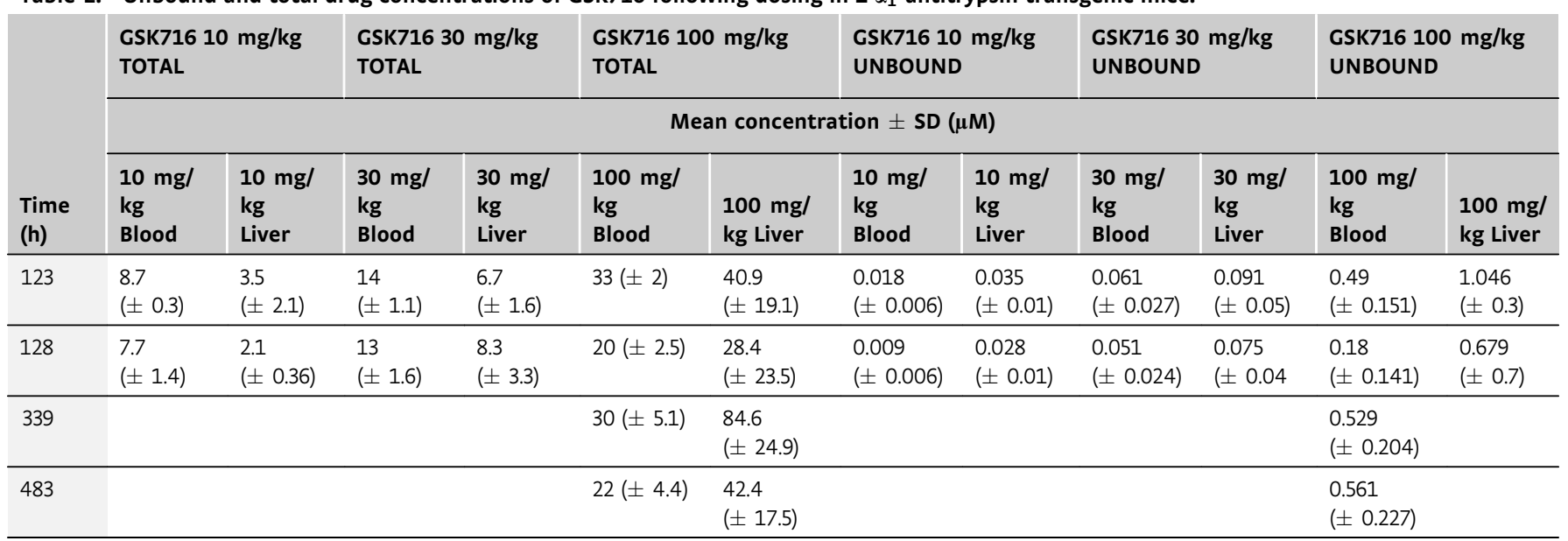

\section{Discussion}

Disrupting protein-protein interactions with small molecule compounds that maintain drug-like properties is a significant challenge. Here, we describe the identification of a potent and selective $\alpha_{1}$-antitrypsin corrector, GSK716 that abolishes intracellular polymerisation of $\mathrm{Z} \alpha_{1}$-antitrypsin and increases the circulating levels of monomeric protein by sevenfold in a transgenic mouse model of disease. The co-crystal structure with $\alpha_{1}$-antitrypsin demonstrates that the small molecule ameliorates the effect of the Glu342Lys (Z) mutation by: (i) optimisation of hydrophobic packing in the breach region; (ii) formation of hydrogen bonds with buried polar atoms; and (iii) displacement of the backbone at the top of strand 5A into a configuration less compatible with partial loop insertion. This movement of strand $5 \mathrm{~A}$ is an early step in reactive loop- $\beta$-sheet A models of polymerisation (Gooptu et al, 2000) and an obligate one in the Cterminal polymer linkage (Yamasaki et al, 2011). Following GSK716 binding, there is a marked stabilisation of $\alpha_{1}$-antitrypsin against the conformational changes associated with $\mathrm{M}^{*}$ intermediate formation. This in turn increases folding efficiency, thereby reducing the formation of polymers. Precedent for this general mechanism comes from our development of a tool monoclonal antibody that exerted a similar effect on $\mathrm{Z} \alpha_{1}$-antitrypsin (Ordóñez et al, 2015; Motamedi-Shad et al, 2016).

The GSK716-associated displacement at the top of strand $5 \mathrm{~A}$ is consistent with the association rate-driven preference for $\mathrm{Z} \alpha_{1}$-antitrypsin and an increased availability of the cryptic pocket. The pocket, once formed, appears to be structurally equivalent in both wild-type $M$ and mutant $\mathrm{Z} \alpha_{1}$-antitrypsin, as reflected by a similar rate of dissociation of GSK716. Binding of GSK716 to $\alpha_{1}$-antitrypsin increased with the propensity of mutants to form polymers ( $\mathrm{M}<\mathrm{S}<$ Baghdad $<\mathrm{Z} \alpha_{1}$-antitrypsin), indicating that pocket formation and polymerisation are intimately linked. GSK716 stabilises the partially folded $\alpha_{1}$-antitrypsin or the fully folded but labile aberrant native form. This mode of action is compatible with the lack of binding of GSK716 to polymers, in which partial or complete insertion of the reactive centre loop completes a $\beta$-hairpin turn and so occludes the compound binding site.

GSK716 blocks $\mathrm{Z} \alpha_{1}$-antitrypsin polymerisation in cell-free media and in the ER of both $\mathrm{CHO}$ and iPSC models of $\alpha_{1}$-antitrypsin deficiency. It increased secretion from the iPSC model by approximately threefold. Treatment with GSK716 reduced the levels of intracellular $\mathrm{Z} \alpha_{1}$-antitrypsin polymer compared with cells assessed before compound addition demonstrating that polymers can be cleared over the time course of the experiment and that accumulation of polymers is reversible in ZZ-iPSC-hepatocytes. These findings were confirmed by pulse-chase experiments which showed that GSK716 abolished intracellular polymers (when assessed by the $2 \mathrm{C} 1$ $\mathrm{mAb}$ ) and increased the clearance and secretion of $\mathrm{Z} \alpha_{1}$-antitrypsin. Dosing of GSK716 in transgenic mice that express $Z \alpha_{1}$-antitrypsin increased circulating levels of $Z \alpha_{1}$-antitrypsin by sevenfold within 3 days, indicating robust target engagement. This effect was maintained to the conclusion of the experiment at day 21 . The increase in $\mathrm{Z} \alpha_{1}$-antitrypsin in the circulation at 10 and $30 \mathrm{mg} / \mathrm{kg}$ of GSK716 was surprising given that systemic free drug levels were below the cellular EC50 for secretion for much or all of the dosing period. The reason for this is unclear but it is possible that the target engagement in vivo is greater than predicted from the potency in the in vitro cellular assays. Alternatively, it is possible that the first-pass effect of drug reaching the liver immediately after absorption delivers some efficacy over that predicted from modelling the compound concentration at steady-state levels. Together, these data suggest potential upsides for the required compound exposure to deliver efficacy in individuals with $\mathrm{Z} \alpha_{1}$-antitrypsin deficiency.

Despite the increase in plasma levels of $Z \alpha_{1}$-antitrypsin, there was no reduction in intrahepatic $\mathrm{Z} \alpha_{1}$-antitrypsin inclusions after 20 days of dosing in the transgenic mouse. This may be because the $\mathrm{Z} \alpha_{1}$-antitrypsin is released from the globule-devoid hepatocytes or because the intrahepatic polymers in the transgenic mice are not cleared as readily as those that are generated over a few days in model systems such as CHO cells and iPSC hepatocytes. Our findings are in contrast to work with the autophagy activator carbamazepine which had profound effects on liver polymer in $\mathrm{Z} \alpha_{1^{-}}$antitrypsin transgenic mice following 2 weeks of dosing (Hidvegi et al, 2010). RNAi approaches that inhibit $\mathrm{Z} \alpha_{1}$-antitrypsin expression and polymer formation have reported decreases in $\mathrm{Z} \alpha_{1}$-antitrypsin in transgenic mouse liver following 12-33 weeks of treatment, albeit without reports of data at earlier timepoints (Guo et al, 2014). It is likely that GSK716 will need to be dosed to 


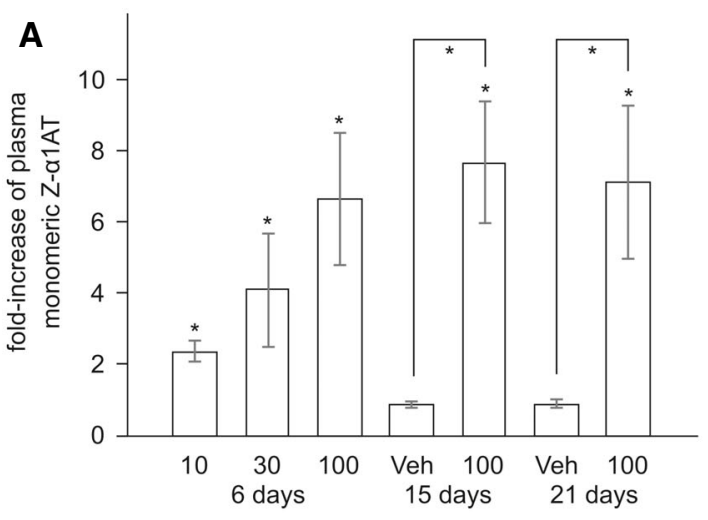

treatment duration and dose $(\mathrm{mg} / \mathrm{kg})$
Total

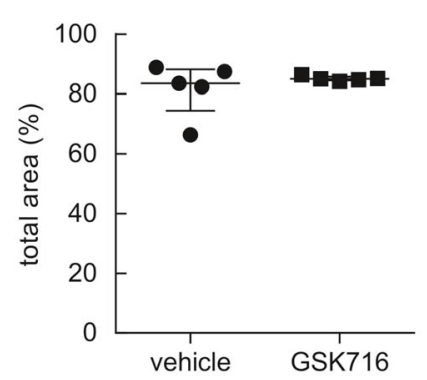

B I
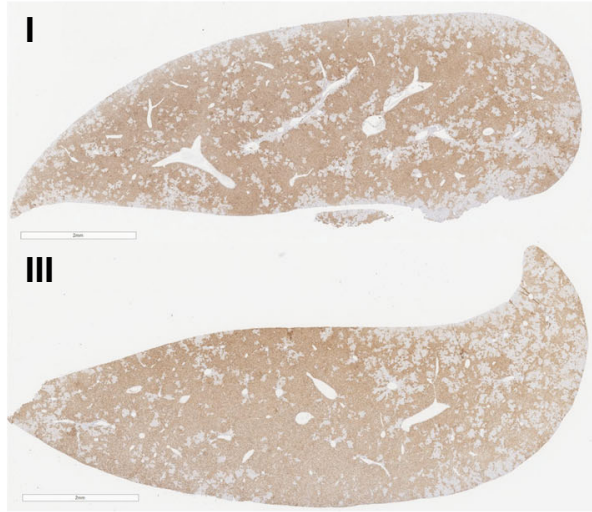

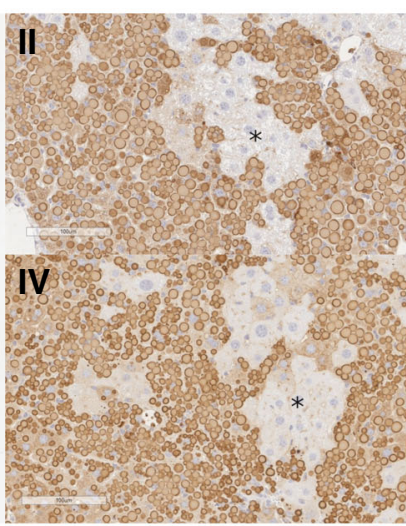

High/mid-intensity
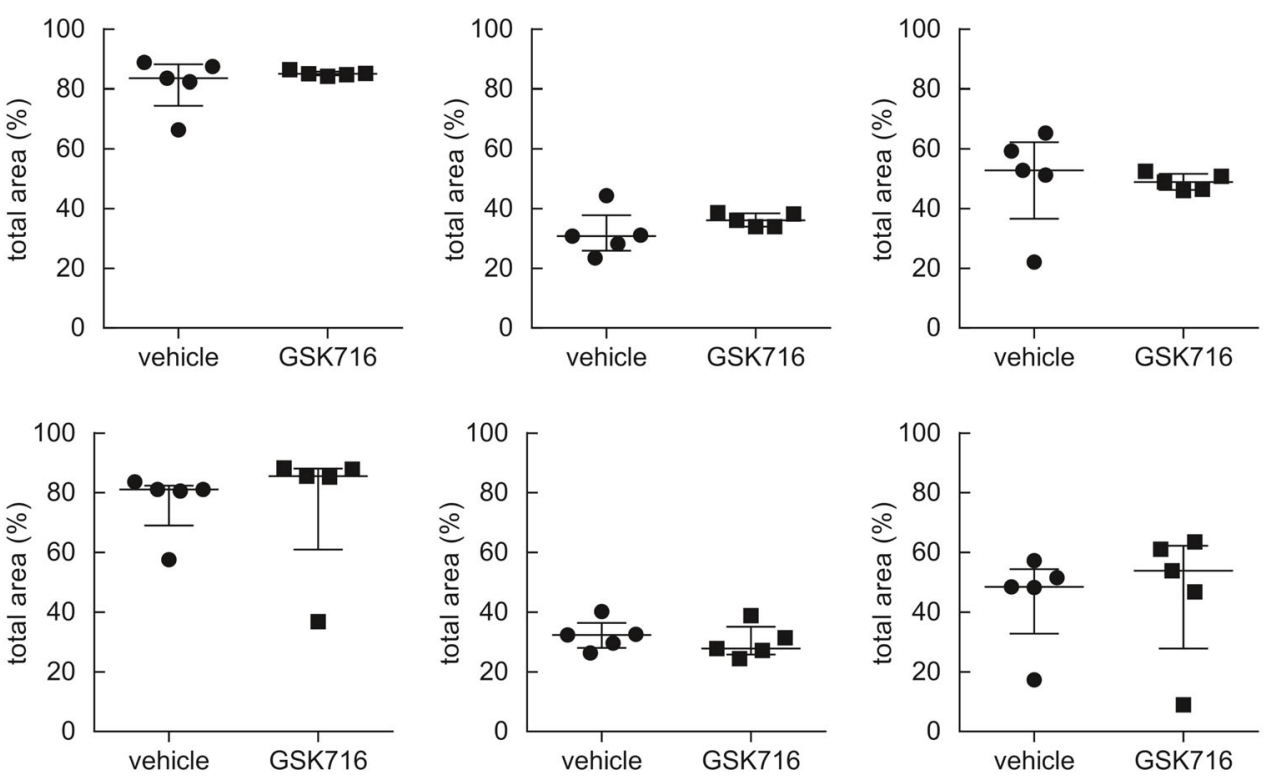

Figure 6. GSK716 increases secretion of $Z \alpha_{1}$-antitrypsin in a transgenic mouse model of $Z \alpha_{1}$-antitrypsin deficiency.

$\mathrm{Z} \alpha_{1}$-antitrypsin transgenic animals were dosed with 10,30 or $100 \mathrm{mg} / \mathrm{kg}$ GSK716 three times a day. Total concentrations of GSK716 were determined by LC-MS/MS (Table 2)

A $100 \mathrm{mg} / \mathrm{kg}$ GSK716 resulted in a mean sevenfold increase in circulating monomeric $Z \alpha_{1}$-antitrypsin levels demonstrating robust target engagement in the liver. The observed steady-state total and free compound levels of GSK716 in the transgenic Z $\alpha_{1}$-antitrypsin mouse were well-predicted by the in silico PK model built on: (i) in vitro metabolic clearance data, (ii) plasma protein binding data, (iii) in vivo PK data from wild-type mice and (iv) a term comprising a $5 \mu \mathrm{M}$ circulating sink for drug with an affinity of $1.5 \mathrm{nM}$, representing the $Z \alpha_{1}$-antitrypsin within blood. The target-free drug concentration was selected based on the observed potency in the in vitro secretion assays in which the total drug approximates to the free drug in the assay. Interestingly, $30 \mathrm{mg} / \mathrm{kg}$ and $10 \mathrm{mg} / \mathrm{kg}$ groups also gave significant, dosedependent increases in circulating $Z \alpha_{1}$-antitrypsin despite free concentrations being below the cellular EC50 for secretion for much or all of the dosing period. Significance at $P<0.05$ by a Student $t$-test is denoted by *, shown as pairwise comparisons (each animal is compared with itself, treated vs pre-treatment) and between groups (compound treated vs vehicle), with $n=7,8$ and 8 per group for day 6 dose level 10, 30 and $100 \mathrm{mg} / \mathrm{Kg}$, respectively; day $15, n=10 ;$ day $21, n=5$. Data presented as mean \pm SD.

B Representative example images of 2C1-stained livers from a 20-day vehicle ( $\mathrm{i}$ and ii) and $100 \mathrm{mg} / \mathrm{kg}$ TID GSK716 (iii and iv)-treated animals. The asterisks indicate regions of hepatocytes that are negative on $2 \mathrm{Cl}$ immunostaining. Scale bar (i) and (iii) $2 \mathrm{~mm}$ and (ii) and (iv) $100 \mu \mathrm{m}$.

C Quantification of 2C1 stained area in livers from vehicle and $100 \mathrm{mg} / \mathrm{kg}$ TID GSK716-treated animals at day 15 (top) and 21 (bottom), shown as total area and lowonly or high and mid-only intensity-stained areas. There were no significant differences between groups by Mann-Whitney U-test; graphs show median \pm interquartile ranges, with $n=5$ per group.

transgenic $\mathrm{Z} \alpha_{1}$-antitrypsin mice for significantly longer than 20 days to demonstrate an effect on total liver polymer levels. It remains to be seen whether the intrahepatic polymer needs to be cleared from the liver in order to have some functional benefit or whether the accumulated polymer inclusions are inert and abrogation of polymer production is sufficient to restore the functioning of the ER and hence the health of the cells. Moreover, treatment with GSK716 may be sufficient to protect against the two-hit process 
whereby the $\mathrm{Z} \alpha_{1}$-antitrypsin polymers sensitise the liver to a secondary insult such as alcohol, drug or liver fat (Ordóñez et al, 2013; Strnad et al, 2019).

Polymer formation and inhibitory activity are inextricably linked in the serpin mechanism (Gooptu \& Lomas, 2009), and thus, small molecules that block polymerisation may have the unwanted effect of also blocking inhibitory activity. Bound GSK716 inhibits the serpin activity of $\alpha_{1}$-antitrypsin and so would not be expected to increase protease inhibitory activity during the dosing period. However, the half-life of monomeric Z- $\alpha_{1}$-antitrypsin in humans is $\sim 6$ days whereas the drug would be expected to be cleared with a half-life of a few hours after dosing, raising the possibility of a pulsatile dosing regimen that would lead to increased, active serpin. The slow development of the lung disease in individuals with $\alpha_{1}$ antitrypsin deficiency over many decades suggests that acute effects associated with inhibition of serpin activity are unlikely.

There is increasing recognition that heterozygosity for wild-type $\mathrm{M}$ and mutant $\mathrm{Z} \alpha_{1}$-antitrypsin alleles predisposes to liver disease (Strnad et al, 2019). Our small molecule approach to block polymer formation has an advantage over siRNA therapies to "knockdown" $\alpha_{1}$-antitrypsin production in treating the MZ $\alpha_{1}$-antitrypsin heterozygote. GSK716 has a 100 -fold greater affinity for Z than $M \alpha_{1}$-antitrypsin and so may be dosed at a level that prevents polymerisation of $Z \alpha_{1}$-antitrypsin without reducing the inhibitory effect of the wildtype $M$ protein.

In summary, we report the first small molecule drug-like correctors of $\mathrm{Z} \alpha_{1}$-antitrypsin folding obtained via optimisation of hits from an encoded library technology screen (Clark et al, 2009; AricoMuendel, 2016; Goodnow et al, 2017) that are suitable for oral delivery, correct folding in human patient iPSC-derived hepatocytes and increase circulating $\mathrm{Z} \alpha_{1}$-antitrypsin levels in a transgenic mouse model of $\alpha_{1}$-antitrypsin deficiency.

\section{Materials and Methods}

Alpha $_{1}$-antitrypsin was purified from the plasma of $M$ (wild-type) and $\mathrm{Z} \alpha_{1}$-antitrypsin homozygotes, and recombinant Cys232Ser $\alpha_{1}$ antitrypsin was expressed and purified as detailed previously (Lomas et al, 1993; Irving et al, 2011; Haq et al, 2013). The data generated in this manuscript have used a number of different preparations of GSK716 all of which have been checked for identity and purity by NMR/MS. Moreover, all batches have been tested for activity in blocking $\alpha_{1}$-antitrypsin polymerisation in the assay as shown in Fig 1B. Full experimental procedures and analytical data for synthesising GSK716 are available in patent WO2019/243841A1 ("compound 1"). The experiments conformed to the principles set out in the WMA Declaration of Helsinki and the Department of Health and Human Services Belmont Report. All animal studies were ethically reviewed and carried out in accordance with European Directive 2010/63/EEC and the GSK Policy on the Care, Welfare and Treatment of Animals, or by the ethical review process at the institution where the work was performed.

\section{DNA-encoded library technology screen}

An encoded library technology (ELT) screen with a nominal diversity of $2 \times 10^{12}$ unique components was used to identify small molecules that bind monomeric $\mathrm{Z} \alpha_{1}$-antitrypsin at 4,22 and $37^{\circ} \mathrm{C}$ Affinity selections were performed as described previously (Clark et al, 2009).

\section{In vitro assay of $\mathrm{Z} \alpha_{1}$-antitrypsin polymerisation}

An antibody-based time-resolved fluorescence resonance energy transfer (TR-FRET) assay was developed to monitor the polymerisation of $5 \mathrm{nM} \mathrm{Z} \alpha_{1}$-antitrypsin following incubation with varying concentrations of compounds at $37^{\circ} \mathrm{C}$ for $72 \mathrm{~h}$. This assay used the $2 \mathrm{Cl}$ monoclonal antibody $(1.25 \mathrm{nM})$ that is specific to pathological polymers of $\alpha_{1}$-antitrypsin (Miranda et al, 2010), a polyclonal antibody (1/320 dilution) that binds to all forms of $\alpha_{1^{-}}$ antitrypsin (Abcam product 9373), an anti-mouse IgG (1.5 nM) labelled with fluorescence donor Eu-W1024 (Perkin Elmer product AD0076) and an anti-rabbit IgG (14.3 nM labelled with acceptor [APC]). In the presence of polymeric $\mathrm{Z} \alpha_{1}$-antitrypsin, a 4-antibody sandwich is formed allowing energy transfer to occur between the Europium- and Allophycocyanin fluorophores. The TR-FRET signal was read on an Envision plate reader (PerkinElmer), by excitation of Europium at $337 \mathrm{~nm}$ and detection of emission at 665 and $620 \mathrm{~nm}$.

\section{Compound association experiments}

Kinetic parameters of GSK716 binding to M, Z, S (Glu264Val) and Baghdad (Ala336Pro) (Haq et al, 2016) $\alpha_{1}$-antitrypsin were measured by detecting intrinsic tryptophan fluorescence of the protein (excitation at $280 \mathrm{~nm}$ and detection of emission at $320 \mathrm{~nm}$ ) on a stopped flow apparatus (Applied Photophysics) (Kim \& Yu, 1996; Dafforn et al, 1999). A competition assay for binding to $M \alpha_{1^{-}}$ antitrypsin and $\mathrm{Z} \alpha_{1}$-antitrypsin and $\mathrm{Z} \alpha_{1}$-antitrypsin polymers (Lomas et al, 1993; Irving et al, 2011; Haq et al, 2013), based on an Alexa488-labelled analogue of GSK716 (A488-GSK716), was used to determine the binding affinity of test compounds.

\section{Thermal stability, unfolding and assessment of protease inhibition}

The native state stability of $\alpha_{1}$-antitrypsin on addition of compounds was investigated by thermal denaturation in the presence of a $5 \mathrm{X}$ concentration of SYPRO Orange dye solution (Life Technologies) (Nettleship et al, 2008). Resistance to heat-induced polymerisation was determined using an end-point constanttemperature assay. Equilibrium unfolding was evaluated with a bis-ANS dye (Dafforn et al, 1999), and rapid refolding following denaturation in $6 \mathrm{M}$ urea was assessed by non-denaturing PAGE. The inhibitory activity of $\alpha_{1}$-antitrypsin was measured by titration against the model protease bovine $\alpha$-chymotrypsin. The activity of antithrombin, neuroserpin and $\alpha_{1}$-antichymotrypsin was assessed against human thrombin, bovine trypsin and bovine $\alpha$-chymotrypsin, respectively.

\section{Crystallisation and structure determination}

Crystallisation of recombinant Cys232Ser $\alpha_{1}$-antitrypsin was carried out in 2-well MRC crystallisation plates with a Mosquito robot (TTP Labtech) using $100 \mathrm{nl}$ protein solution and $100 \mathrm{nl}$ well solution. 
Crystals grew from 22\% w/v PEG1500, 0.2 M MES pH6.0 and were soaked for $24 \mathrm{~h}$ with $25 \mathrm{mM}$ compound ( $5 \% \mathrm{v} / \mathrm{v}$ DMSO). X-ray diffraction data were collected at Diamond on beamline I03. Structure solution was carried out by molecular replacement using PHASER (McCoy et al, 2007). The model used to solve this structure was a related complex (data not shown) which had been solved by molecular replacement using PDB entry 2QUG as a starting model. Building was carried out using Coot (Emsley et al, 2010) and refinement with REFMAC (Murshudov et al, 1997).

\section{In vitro pharmacokinetics}

ChromLogD was measured as previously described (Valkó et al, 1997).

\section{Permeability in MDR1-MDCK cells with pgp inhibitor}

MDR1-MDCK cells were used between passage numbers 6-30. Cells were seeded onto Millipore Multiscreen Transwell plates at $3.4 \times 105$ cells $/ \mathrm{cm}^{2}$. The cells were cultured in DMEM and media was changed on day 3 . On day 4 the permeability study was performed. Cell culture and assay incubations were carried out at $37^{\circ} \mathrm{C}$ in an atmosphere of $5 \% v / v \mathrm{CO}_{2}$ with a relative humidity of $95 \%$. On the day of the assay, the monolayers were prepared by rinsing both apical and basolateral surfaces twice with Hanks Balanced Salt Solution (HBSS) at the desired $\mathrm{pH}$ warmed to $37^{\circ} \mathrm{C}$. Cells were then incubated with HBSS at the desired $\mathrm{pH}$ in both apical and basolateral compartments for $40 \mathrm{~min}$ to stabilise physiological parameters. Where applicable, a P-gp inhibitor (elacridar, $2 \mu \mathrm{M}$ ) was included on both sides of the monolayer for the equilibration period. For assessment of apical-basolateral permeability, HBSS was removed from the apical compartment and replaced with test compound dosing solution. The apical compartment insert was then placed into a companion plate containing fresh buffer (containing $0.5 \% v / v$ DMSO or, where applicable, a P-gp inhibitor, maintaining a $0.5 \% \quad v / v$ DMSO concentration). For assessment of basolateral-apical permeability, HBSS was removed from the companion plate and replaced with test compound dosing solution. Fresh buffer (containing $0.5 \% v / v$ DMSO or, where applicable, a Pgp inhibitor, maintaining a $0.5 \% \quad v / v$ DMSO concentration) was added to the apical compartment insert, which was then placed into the companion plate. At $60 \mathrm{~min}$ the apical compartment inserts and the companion plates were separated and apical and basolateral samples diluted for analysis.

\section{CYP3A4 TDI fold IC50 shift}

Seven concentrations of GSK716 $(2,4,10,20,40,100$ and $200 \mu \mathrm{M})$ plus a vehicle control $(0.25 \% v / v$ DMSO in pre-incubation) were pre-incubated at $37^{\circ} \mathrm{C}$ with human liver microsomes $(0.1 \mathrm{mg} / \mathrm{ml})$ and NADPH $(1 \mathrm{mM})$ for a range of five pre-incubation times $(5,10$, 15,20 and $30 \mathrm{~min}$ ) with a $0 \mathrm{~min}$ pre-incubation, in duplicate. At the end of the individual pre-incubations, an aliquot of the pre-incubation mixture was added to an incubation mixture in a 1:20 dilution for GSK716 with the specific CYP3A4 probe substrate, midazolam $(12.5 \mu \mathrm{M}$, equivalent to $5 \mathrm{xKm} 44)$ and NADPH $(1 \mathrm{mM})$ for a $5 \mathrm{~min}$. The reactions were terminated by transferring an aliquot of incubation mixture to methanol. The samples were mixed and then centrifuged at $2,500 \mathrm{rpm}$ for $30 \mathrm{~min}$ at $4^{\circ} \mathrm{C}$. Aliquots of the supernatant were diluted with formic acid (final concentration $0.1 \% v / v$ ) in deionised water containing internal standard (metoprolol; final concentration $0.03 \mathrm{mg} / \mathrm{l}$ ). Samples were analysed by LC-MS/MS.

\section{Hepatocyte clearance}

Williams E media supplemented with $2 \mathrm{mM}$ L-glutamine and $25 \mathrm{mM}$ HEPES and test compound (final compound concentration $0.5 \mu \mathrm{M}$; final DMSO concentration $0.25 \% v / v$ ) were preincubated at $37^{\circ} \mathrm{C}$ prior to the addition of a suspension of cryopreserved pooled hepatocytes (final cell density $0.5 \times 106$ viable cells $/ \mathrm{ml}$ ) to initiate the reaction. The final incubation volume was $500 \mu$ l. The reactions were stopped by transferring $50 \mu \mathrm{l}$ of incubate to $100 \mu$ l acetonitrile containing internal standard at the appropriate time points $(0,5,10,20,40$ and $60 \mathrm{~min}, 0,10,20,40,60$ and $120 \mathrm{~min}$ or $0,20,40,60,120$ and $240 \mathrm{~min}$ ). The control (lysed cells or vehicle) was incubated for 60 , 120 or $240 \mathrm{~min}$ only. The termination plates were centrifuged at 2,500 rpm at $4^{\circ} \mathrm{C}$ for $30 \mathrm{~min}$ to precipitate the protein. Following protein precipitation, the sample supernatants were analysed by LC-MS/MS. From a plot of loge peak area ratio (compound peak area/ internal standard peak area) against time, the gradient of the line was determined and half-life $\left(t^{1} / 2\right)$ and intrinsic clearance (CLint) were calculated.

\section{Measurement of monomeric $\mathrm{Z} \alpha_{1}$-antitrypsin in plasma and cell biology}

Plasma standards of monomeric and polymeric $\mathrm{Z} \alpha_{1}$-antitrypsin were prepared and assayed with an antibody mix comprising a $1: 160$ dilution of rabbit polyclonal anti- $\alpha_{1}$-antitrypsin (Abcam product 9373), $0.23 \mu \mathrm{g} / \mathrm{ml}$ terbium anti-mouse, $4.5 \mu \mathrm{g} / \mathrm{ml}$ Alexa488 goat anti-rabbit, $0.17 \mu \mathrm{g} / \mathrm{ml}$ mouse anti-total- $\alpha_{1}$-antitrypsin monoclonal 3C11 and $2 \mu \mathrm{g} / \mathrm{ml}$ mouse $2 \mathrm{C} 1$ anti-polymeric- $\alpha_{1}$-antitrypsin. After a 16 -h incubation at $20^{\circ} \mathrm{C}$, TR-FRET detection was performed on an Envision plate reader (Perkin Elmer).

Plots of the FRET ratio (acceptor/donor signal) versus sample dilution result in bell-shaped curves due to the hook effect. The polymer $\mathrm{Z} \alpha_{1}$-antitrypsin concentration was determined by comparing the peak positions of these bell-shaped curves for plasma samples with those for polymer calibration samples. The polymer concentration in the plasma sample and the polymer calibration curve was then used to derive the contribution of polymer to the FRET signal in the total $\alpha_{1}$-antitrypsin assay at the signal peak, enabling determination of the concentration of monomeric $\mathrm{Z} \alpha_{1}$-antitrypsin.

\section{$Z \alpha_{1}$-antitrypsin secretion / polymerisation in CHO-TET-ON-Z- $\alpha_{1} A T$ cells}

The accumulation and clearance of $\mathrm{Z} \alpha_{1}$-antitrypsin polymer was measured with the $2 \mathrm{C} 1$ monoclonal antibody that is specific for polymerised antitrypsin in CHO-TET-ON-Z- $\alpha_{1}$ AT cells (Ordóñez et al, 2013) and iPSC-derived hepatocytes generated from a patient with a PiZZ genotype (Yusa et al, 2011). Secretion of $\mathrm{Z} \alpha_{1}$-antitrypsin was determined by TR-FRET. Cell viability was analysed with Cell Counting Kit-8 (Sigma) after treating the cells with $10 \mu \mathrm{M}$ GSK716 or $0.1 \% \mathrm{v} / \mathrm{v}$ DMSO (vehicle) and an increasing concentration of tunicamycin $(0.8-0.01 \mu \mathrm{g} / \mathrm{ml})$.

\section{Pulse chase experiments}

CHO K1 cells were labelled after 48-h induction with $0.5 \mu \mathrm{g} / \mathrm{ml}$ doxycycline. Cells were pulsed $\left(0.45 \mathrm{MBq} / 10^{6}\right.$ cells $)$ for $10 \mathrm{~min}$ with 


\section{The paper explained}

\section{Problem}

Intracellular protein aggregation can result in "gain-of-function" cell toxicity. It has proved challenging to develop small molecules that can stabilise intracellular mutant proteins, prevent self-aggregation and so ameliorate disease. Severe $\alpha_{1}$-antitrypsin deficiency results largely from the $Z$ allele (Clu342Lys) that causes the accumulation of homopolymers of mutant $\alpha_{1}$-antitrypsin within the endoplasmic reticulum of hepatocytes in association with liver disease.

\section{Results}

We have undertaken a medicinal chemistry campaign to develop an orally bioavailable small molecule that binds to intra-endoplasmic reticulum mutant $Z \alpha_{1}$-antitrypsin, corrects the folding defect and increases secretion in a transgenic model of disease.

\section{Impact}

This study reports the successful targeting of an aggregation-prone mutant in order to prevent the intracellular polymerisation and accumulation of $\alpha_{1}$-antitrypsin that underlies $\alpha_{1}$-antitrypsin deficiency. It demonstrates that "mutation ameliorating" small molecules can block the aberrant polymerisation that underlies $Z \alpha_{1}$-antitrypsin deficiency.

${ }^{35}$ S Cys/Met (EasyTagTM Express Protein Labelling, Perkin Elmer, Beaconsfield, UK) in DMEM without Cys/Met, and then chased in normal culture medium for $0,1,4,8$ and $12 \mathrm{~h}$. Radiolabelled $\alpha_{1}$ antitrypsin was isolated by immunoprecipitation and resolved by SDS-PAGE followed by autoradiography. Densitometric analysis of $\alpha_{1}$-antitrypsin bands was performed with ImageStudioLite (LI-COR Biosciences, USA). Statistical analysis was performed using the GraphPad Prism program (GraphPad Software, La Jolla, CA, USA).

\section{In vivo experiments}

\section{Pharmacokinetics}

Male CD-1 mice, Han Wistar rats or beagle dogs were administered GSK716 as a suspension in $1 \% \mathrm{w} / \mathrm{v}$ aqueous methylcellulose via oral gavage at doses of $1 \mathrm{mg} / \mathrm{kg}$ (dog) or 10,30 and $100 \mathrm{mg} / \mathrm{kg}$ (mouse, rat). Blood samples were taken into EDTA, diluted and mixed with acetonitrile containing internal standard (alprazolam) and centrifuged to precipitate proteins. Aliquots of the resultant supernatant were analysed by LC-MS/MS, and concentrations of GSK716 in blood were determined. Non-compartmental pharmacokinetic analysis (NCA) was carried out using Phoenix WinNonLin 6.3 (Certara L.P.). Free drug was measured in $Z \alpha_{1}$-antitrypsin transgenic mice by dialysing tissue samples in rapid equilibrium dialysis cassettes.

\section{$Z \alpha_{1}$-antitrypsin transgenic mouse experiments}

Hemizygous female $\mathrm{Z} \alpha_{1}$-antitrypsin transgenic mice were 1315 weeks of age at start of study. Drugs were administered via oral gavage three times a day at 8 -h intervals at $10 \mathrm{ml} / \mathrm{Kg}$ as a suspension in aqueous methylcellulose containing $0.5 \% \mathrm{w} / \mathrm{v}$ Tween 80 . In life, blood sampling was performed vial tail nick. Animals were housed in licensed, approved housing in the UK with appropriate enrichment. Animals were randomly assigned to groups using manual methods. Histopathology analysis was performed blind.

\section{Histopathology, immunohistochemistry and image analysis}

Formalin-fixed, paraffin-embedded livers from all mice were sectioned and stained with haematoxylin and eosin (H\&E) and periodic acid Schiff (PAS) with diastase to examine tissue quality and the presence of diastase-resistant polymer inclusions, respectively. Immunohistochemistry for polymerised $\alpha_{1}$-antitrypsin was performed using 2C1 monoclonal primary antibody and a Mouseon-Mouse Polymer Kit (Abcam AB127055) for detection. Representative sections of liver from each mouse were blindly evaluated by a Board-Certified Veterinary Pathologist and ranked in order of polymer content. A semi-automated image analysis solution was developed to quantify total polymer content (Fig EV1). Thresholds were optimised to separate staining of the polymer inclusions (high and medium intensity) and more diffuse cytoplasmic staining (low intensity).

\section{Statistics}

Formal power calculations were not performed for in vivo studies but $n$ numbers were determined based on prior experience with the model and readout. Animals were randomly assigned to groups, using manual methods not randomisation tools. In vivo work was performed by individuals unfamiliar with the project, and ex vivo analysis was performed by different scientists to those executing the in life phase. Histopathology analysis was performed blinded.

\section{Data availability}

The data set produced in this study: alpha 1-antitrypsin (C232S) complexed with GSK716 is available in the PDB identifier 7AEL (http://www.rcsb.org/pdb/explore/explore.do?structureId=7AEL).

Expanded View for this article is available online.

\section{Acknowledgements}

We are very grateful to Jeff Teckman, Department of Pediatrics, Saint Louis University, MO, USA, for providing the transgenic mouse model of $\alpha_{1}$-antitrypsin deficiency. Riccardo Ronzoni and Imran Haq were supported by GlaxoSmithKline. Alistair Jagger is the recipient of a BBSRC CASE studentship. This work was supported by GlaxoSmithKline, the Medical Research Council (UK) (MR/N024842/1), Alpha-1 Awareness and the UCLH NIHR Biomedical Research Centre. DAL is an NIHR Senior Investigator. Data collection was performed on beamline 103 at the Diamond Light Source, and the authors would like to thank the staff for facility access and technical support.

\section{Author contributions}

$D A L, A B$ and $A C P$ designed the programme of work. DAL, ACP, JAI, IU and DSH served on the joint UCL-GSK DPAC project oversight board. JAI, IH, AJ, $A D o, D K, J P H, M R$, JR and $M B$ undertook the biochemical assessment of the compounds; AOr, SJM, AD, MR, TJ and RR assessed the cell biology; CC, KJS and $M N$ undertook structural biology studies; CA-M, SB, JM, AOI, ZZ, SS and $K L$ undertook encoded library technology screening; $H D, P E, E J, R T, L T$ and SW undertook $\mathrm{PK}$, in vivo profiling and pathology and; $A B, A D e, N D, D S H$ and $\mathrm{JL}$ undertook medicinal chemistry. All authors reviewed, revised and approved the final manuscript. 


\section{Conflict of interest}

Kate Smith, Alexis Denis, Nerina Dodic, John Liddle and David Lomas are inventors on patent PCT/GB2019/051761. The intellectual property has been transferred from GlaxoSmithKline to UCL Business who have licensed it to a third party.

\section{For more information}

https://www.omim.org/entry/613490

https://www.alpha1.org, https://www.alpha1.uk

\section{References}

Arico-Muendel CC (2016) From haystack to needle: finding value with DNA encoded library technology at GSK. Med Chem Commun 7: 1898-1909

Clark MA, Acharya RA, Arico-Muendel CC, Belyanskaya SL, Benjamin DR, Carlson NR, Centrella PA, Chiu CH, Creaser SP, Cuozzo JW et al (2009) Design, synthesis and selection of DNA-encoded small-molecule libraries. Nat Chem Biol 5: 647-654

Dafforn TR, Mahadeva R, Elliott PR, Sivasothy P, Lomas DA (1999) A kinetic mechanism for the polymerisation of a1-antitrypsin. J Biol Chem 274: $9548-9555$

Ekeowa UI, Freekeb J, Miranda E, Gooptu B, Bush MF, Pérez J, Teckman J, Robinson CV, Lomas DA (2010) Defining the mechanism of polymerization in the serpinopathies. Proc Natl Acad Sci USA 107: 17146-17151

Emsley P, Lohkamp B, Scott WG, Cowtan K (2010) Features and development of Coot. Acta Crystallogr D Biol Crystallogr 66(Pt 4): 486-501

Faull SV, Elliston ELK, Gooptu B, Jagger AM, Aldobiyan I, Redzej A, Badaoui M, Heyer-Chauhan N, Rashid ST, Reynolds GM et al (2020) The structural basis for $Z \alpha 1$-antitrypsin polymerisation in the liver. Sci Adv 6: eabc1370

Goodnow Jr RA, Dumelin CE, Keefe AD (2017) DNA-encoded chemistry: enabling the deeper sampling of chemical space. Nat Reu Drug Discou 16: $131-147$

Gooptu B, Hazes B, Chang W-SW, Dafforn TR, Carrell RW, Read R, Lomas DA (2000) Inactive conformation of the serpin $\alpha 1$-antichymotrypsin indicates two stage insertion of the reactive loop; implications for inhibitory function and conformational disease. Proc Natl Acad Sci USA 97: 67-72

Cooptu B, Lomas DA (2009) Conformational pathology of the serpins - themes, variations and therapeutic strategies. Annu Rev Biochem 78: 147-176

Guo S, Booten SL, Aghajan M, Hung C, Zhao C, Blomenkamp K, Gattis D, Watt A, Freier SM, Teckman JH et al (2014) Antisense oligonucleotide treatment ameliorates alpha-1 antitrypsin-related liver disease in mice. J Clin Invest 124: $251-261$

Haq I, Irving JA, Faull SV, Dickens JA, Ordóñez A, Belorgey D, Gooptu B, Lomas DA (2013) Reactive centre loop mutants of $\alpha$-1-antitrypsin reveal positionspecific effects on intermediate formation along the polymerization pathway. Biosci Rep 33: e00046

Haq I, Irving JA, Saleh AD, Dron L, Regan-Mochrie GL, Motamedi-Shad N, Hurst JR, Gooptu B, Lomas DA (2016) Deficiency mutations of $\alpha 1$ antitrypsin differentially affect folding, function and polymerization. Am J Resp Cell Mol Biol 2016: 71-80

Hidvegi T, Ewing M, Hale P, Dippold C, Beckett C, Kemp C, Maurice N, Mukherjee A, Goldbach C, Watkins S et al (2010) An autophagy-enhancing drug promotes degradation of mutant alpha1-antitrypsin $\mathrm{Z}$ and reduces hepatic fibrosis. Science 329: 229-232

Hood DB, Huntingdon JA, Gettins PCW (1994) $a_{1}$-proteinase inhibitor variant T345R. Influence of P14 residue on substrate and inhibitory pathways. Biochemistry 33: $8538-8547$
Huang X, Zheng Y, Zhang F, Wei Z, Wang Y, Carrell RW, Read RJ, Chen GQ, Zhou A (2016) Molecular mechanism of $Z$ al-antitrypsin deficiency. J Biol Chem 291: 15674-15686

Irving JA, Ekeowa UI, Belorgey D, Haq I, Gooptu B, Miranda E, Pérez J, Roussel BD, Ordóñez A, Dalton LE et al (2011) The serpinopathies: studying serpin polymerization in vivo. Methods Enzymol 501: 421-466

Irving JA, Haq I, Dickens JA, Faull SV, Lomas DA (2014) Altered native stability is the dominant basis for susceptibility of $\alpha 1$-antitrypsin mutants to polymerization. Biochem J 460: 103-115

Irving JA, Miranda E, Haq I, Perez J, Kotov VR, Faull SV, Motamedi-Shad N, Lomas DA (2015) An antibody raised against a pathogenic serpin variant induces mutant-like behaviour in the wild-type protein. Biochem J 468: 99-108

James EL, Bottomley SP (1998) The mechanism of $\alpha 1$-antitrypsin polymerization probed by fluorescence spectroscopy. Arch Biochem Biophys 356: $296-300$

Kim D, Yu M-H (1996) Folding pathway of human $\alpha 1$-antitrypsin : characterisation of an intermediate that is active but prone to aggregation. Biochem Biophys Res Commun 226: 378-384

Knaupp AS, Levina V, Robertson AL, Pearce MC, Bottomley SP (2010) Kinetic instability of the serpin $Z \alpha 1$-antitrypsin promotes aggregation. J Mol Biol 396: $375-383$

Laffranchi M, Elliston ELK, Miranda E, Perez J, Ronzoni R, Jagger AM, Heyer-Chauhan N, Brantly ML, Fra A, Lomas DA et al (2020) Intrahepatic heteropolymerisation of $\mathrm{M}$ and $\mathrm{Z}$ alpha-1-antitrypsin. $\mathrm{JCI}$ Insight 5: 135459

Le A, Ferrell GA, Dishon DS, Quyen-Quyen AL, Sifers RN (1992) Soluble aggregates of the human PiZ $\alpha 1$-antitrypsin variant are degraded within the endoplasmic reticulum by a mechanism sensitive to inhibitors of protein synthesis. J Biol Chem 267: 1072-1080

Lomas DA, Evans DL, Finch JT, Carrell RW (1992) The mechanism of Z $\alpha 1$ antitrypsin accumulation in the liver. Nature 357: 605-607

Lomas DA, Evans DL, Stone SR, Chang W-SW, Carrell RW (1993) Effect of the $\mathrm{Z}$ mutation on the physical and inhibitory properties of $\alpha 1$-antitrypsin. Biochemistry 32: $500-508$

Lomas DA, Hurst JR, Gooptu B (2016) Update on alpha-1 antitrypsin deficiency: new therapies. J Hepatol 65: 413-424

McCoy AJ, Grosse-Kunstleve RW, Adams PD, Winn MD, Storoni LC, Read RJ (2007) Phaser crystallographic software. J Appl Cryst 40: 658-674

Miranda E, Pérez J, Ekeowa UI, Hadzic N, Kalsheker N, Gooptu B, Portmann B, Belorgey D, Hill M, Chambers S et al (2010) A novel monoclonal antibody to characterise pathogenic polymers in liver disease associated with $\alpha 1$ antitrypsin deficiency. Hepatology 52: 1078-1088

Motamedi-Shad N, Jagger AM, Liedtke M, Faull SV, Nanda AS, Salvadori E, Wort JL, Kay CW, Heyer-Chauhan N, Miranda E et al (2016) An antibody that prevents serpin polymerisation acts by inducing a novel allosteric behaviour. Biochem J 473: 3269-3290

Murshudov GN, Vagin AA, Dodson EJ (1997) Refinement of macromolecular structures by the maximum-likelihood method. Acta Cryst D53: $240-255$

Nettleship JE, Brown J, Groves MR, Geerlof A (2008) Methods for protein characterization by mass spectrometry, thermal shift (ThermoFluor) assay, and multiangle or static light scattering. Methods Mol Biol 426: 299-318

Nyon MP, Segu L, Cabrita LD, Lévy GR, Kirkpatrick J, Roussel BD, Patschull AO, Barrett TE, Ekeowa UI, Kerr R et al (2012) Structural dynamics associated with intermediate formation in an archetypal conformational disease. Structure 20: $504-512$ 
Ordóñez A, Snapp EL, Tan L, Miranda E, Marciniak SJ, Lomas DA (2013) Endoplasmic reticulum polymers impair luminal protein mobility and sensitize to cellular stress in alpha1-antitrypsin deficiency. Hepatology 57: 2049-2060

Ordóñez A, Pérez J, Tan L, Dickens JA, Motamedi-Shad N, Irving JA, Haq I, Ekeowa U, Marciniak SJ, Miranda E et al (2015) A single-chain variable fragment intrabody prevents intracellular polymerisation of $Z \alpha 1-$ antitrypsin. FASEB J 29: 2667-2678

Pearce MC, Morton C, Feil SC, Hansen G, Adams JJ, Parker MW, Bottomley SP (2008) Preventing serpin aggregation: the molecular mechanism of citrate action upon antitrypsin unfolding. Protein Sci 17: 2127-2133

Qu D, Teckman JH, Omura S, Perlmutter DH (1996) Degradation of a mutant secretory protein, $\alpha 1$-antitrypsin $Z$, in the endoplasmic reticulum requires proteasome activity. J Biol Chem 271: 22791-22795

Ronzoni R, Heyer-Chauhan N, Fra A, Pearce AC, Rüdiger M, Miranda E, Irving JA, Lomas DA (2020) The molecular species responsible for $\alpha 1$-antitrypsin deficiency are suppressed by a small molecule chaperone. FEBS / https:// doi.org/10.1111/febs.15597

Strnad P, Buch S, Hamesch K, Fischer J, Rosendahl J, Schmelz R, Brueckner S, Brosch M, Heimes CV, Woditsch V et al (2019) Heterozygous carriage of the alpha1-antitrypsin $\mathrm{Pi} Z \mathrm{Z}$ variant increases the risk to develop liver cirrhosis. Gut 68: 1099-1107

Tan L, Dickens JA, Demeo DL, Miranda E, Perez J, Rashid ST, Day J, Ordoñez A, Marciniak SJ, Haq I et al (2014) Circulating polymers in $\alpha 1$-antitrypsin deficiency. Eur Respir J 43: 1501-1504

Teckman JH, Burrows J, Hidvegi T, Schmidt B, Hale PD, Perlmutter DH (2001) The proteasome participates in degradation of mutant $\alpha 1$-antitrypsin $\mathrm{Z}$ in the endoplasmic reticulum of hepatoma-derived hepatocytes. J Biol Chem 276: $44865-44872$

Teckman JH, An JK, Blomenkamp K, Schmidt B, Perlmutter D (2004) Mitochondrial autophagy and injury in the liver in $\alpha 1$-antitrypsin deficiency. Am J Physiol Gastrointest Liver Physiol 286: G851-G862

Valkó K, Bevan C, Reynolds D (1997) Chromatographic hydrophobicity index by fast-gradient RP-HPLC: a high-throughput alternative to log P/log D. Anal Chem 69: 2022-2029

Whisstock JC, Skinner R, Carrell RW, Lesk AM (2000) Conformational changes in serpins: I. The native and cleaved conformations of alpha(1)-antitrypsin. J Mol Biol 295: 651-665

Wu Y, Swulius MT, Moremen KW, Sifers RN (2003) Elucidation of the molecular logic by which misfolded $\alpha 1$-antitrypsin is preferentially selected for degradation. Proc Natl Acad Sci USA 100: 8229-8234

Yamasaki M, Sendall TJ, Pearce MC, Whisstock JC, Huntington JA (2011) Molecular basis of $\alpha 1$-antitrypsin deficiency revealed by the structure of a domain-swapped trimer. EMBO Rep 12: 1011-1017

Yusa K, Rashid ST, Strick-Marchand H, Varela I, Liu PQ, Paschon DE, Miranda E, Ordóñez A, Hannan NR, Rouhani FJ et al (2011) Targeted gene correction of $\alpha 1$-antitrypsin deficiency in induced pluripotent stem cells. Nature 478: $391-394$

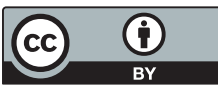

License: This is an open access article under the terms of the Creative Commons Attribution License, which permits use, distribution and reproduction in any medium, provided the original work is properly cited. 